\title{
Group Contribution Based Estimation Method for Properties of Ionic Liquids
}

\section{Chen, Yuqiu; Kontogeorgis, Georgios M.; Woodley, John M.}

Published in:

Industrial and Engineering Chemistry Research

Link to article, DOI:

10.1021/acs.iecr.8b05040

Publication date:

2019

Document Version

Peer reviewed version

Link back to DTU Orbit

Citation (APA):

Chen, Y., Kontogeorgis, G. M., \& Woodley, J. M. (2019). Group Contribution Based Estimation Method for Properties of lonic Liquids. Industrial and Engineering Chemistry Research, 58(10), 4277-4292.

https://doi.org/10.1021/acs.iecr.8b05040

\section{General rights}

Copyright and moral rights for the publications made accessible in the public portal are retained by the authors and/or other copyright owners and it is a condition of accessing publications that users recognise and abide by the legal requirements associated with these rights.

- Users may download and print one copy of any publication from the public portal for the purpose of private study or research.

- You may not further distribute the material or use it for any profit-making activity or commercial gain

- You may freely distribute the URL identifying the publication in the public portal

If you believe that this document breaches copyright please contact us providing details, and we will remove access to the work immediately and investigate your claim. 


\title{
Group contribution-based estimation method for properties of ionic liquids
}

\author{
Yuqiu Chen, Georgios M. Kontogeorgis, John M. Woodley* \\ Department of Chemical and Biochemical Engineering, Technical University of Denmark \\ DK-2800 Lyngby, Denmark
}

\begin{abstract}
Properties of ionic liquids (ILs) are required for the design of products and processes involving ILs. Although innumerable ILs may be generated through the combination of a variety of cations, anions and substituents, only a small part of them have been reported to exist (have been synthesized). The available experimental data are generally limited and sometimes even contradictory. A detailed knowledge about the properties of ILs is critically important, especially for ILs not yet available. Based on collected experimental data from numerous literature sources, a series of group contribution models have been developed for estimating various properties (density, heat capacity, viscosity, surface tension, melting point) of ILs. To evaluate the predictive capability of the proposed or employed group contribution models, nearly $70 \%$ of the datasets (i.e. training sets) are used for correlation, and then the remaining datasets (i.e. test sets) not included in the training sets are used for prediction. The calculation results show that the proposed group contribution models can predict the properties of studied ILs with sufficient accuracy. These property estimation models can both be used easily, and also provide estimation of important properties for previously unstudied ILs, some of which may be considered as potential solvents in many industry applications.
\end{abstract}

\section{Introduction}

Ionic liquids (ILs) are molten salts, which are liquid at ambient temperature and have many attractive features such as almost negligible vapor pressure, low melting point, high thermal and chemical stability, ${ }^{1}$ wide electrochemical window, and also provide good solubility and selectivity for a wide range of materials like organic, inorganic and biomaterials. These characteristics make ILs as potential alternatives to the volatile organic chemicals (VOCs) for applications in chemical, ${ }^{2,3}$ biochemical, ${ }^{4-7}$ pharmaceutical $^{8}$ and electrochemical industry ${ }^{9-12}$ as well as for separation processes (like acid gas removal, ${ }^{13-15}$ extraction, ${ }^{16-18}$ extractive distillation ${ }^{19,20}$ ).

Usually, ILs consist of diverse organic cations where are attached to various substituents and organic or inorganic anions, which result in more than a trillion of possible ILs. Because of this tunable feature, suitable tailor-made ILs containing desired physical and thermophysical properties can be generated by adjusting the cation, anion, and side chains on the cation ${ }^{21}$ for specific applications.

The increasing interest in ILs in chemical, biochemical and other industrial processes requires systematic knowledge of the properties of ILs in order to predict their behavior needed for product and process design involving these compounds. Therefore, study of property characterization and development of structure-property relationships for ILs is as important as the investigation of their applications.

So far, only a limited number of ILs have been reported and the available experimental data of their properties is still scarce and restricted to some well-studied ILs, moreover, experimental data from different sources are sometimes contradictory. Considering the potential of ILs and their very large number, to measure the properties for all conceivable ILs is impractical. Therefore, theoretical or empirical methods are alternative and promising ways to achieve the required information on their properties. 
Currently, a variety of methods have been proposed for estimating the properties of ILs, among them, group contribution methods are popular since they can be easily used and they are also the basis of the development of computer aided molecular design (CAMD) methods, ${ }^{22,23}$ which are useful techniques for confidently identifying optimal ILs containing desired properties for specific applications. $^{24}$

The purpose of this work is to develop reliable group contribution methods for the estimation of several properties (density, heat capacity, viscosity, surface tension and melting point) for ILs. The ultimate target is to be able to use the method not just for well-known ILs but also for the many ILs previously not-studied, which may be considered as potential solvents in practical applications.

A comprehensive database has been created by collection of physical and thermophysical properties of ILs from numerous literature sources and also by a priori generation of new ILs. The following IL ions and substituents are included in this database; cations: imidazolium [Im], pyridinium [Py], pyrrolidinium [Pyr], and alkyl ammonium [Am], alkyl phosphonium [Ph], piperidinium [Pip]; anions: bis(trifluoromethanesulfonyl) amide $\left[\mathrm{Tf}_{2} \mathrm{~N}\right]$, tetrafluoroborate $\left[\mathrm{BF}_{4}\right]$, hexafluorophosphate $\left[\mathrm{PF}_{6}\right]$, chloride $[\mathrm{Cl}]$, acetate $\left[\mathrm{CH}_{3} \mathrm{COO}\right]$, methyl sulfate $\left[\mathrm{MeSO}_{4}\right]$, ethyl sulfate $\left[\mathrm{EtSO}_{4}\right]$, trifluoromethanesulfonate $\left[\mathrm{CF}_{3} \mathrm{SO}_{3}\right]$, bromide $[\mathrm{Br}]$, trifluoroacetate $\left[\mathrm{CF}_{3} \mathrm{COO}\right]$, dicyanamide $\left[\mathrm{N}(\mathrm{CN})_{2}\right]$, tricyanomethanide $\left[\mathrm{C}(\mathrm{CN})_{3}\right]$, tetrachloroalluminate $\left[\mathrm{AlCl}_{4}\right]$, tetrachloroindate $\left[\mathrm{InCl}_{4}\right]$, dimethylphosphate $\left[\left(\mathrm{CH}_{3}\right)_{2} \mathrm{PO}_{4}\right]$, tetrachloroironate $\left[\mathrm{FeCl}_{4}\right]$, tetrachlorogallate $\left[\mathrm{GaCl}_{4}\right]$, and bis(perfluoroethylsulfonyl)imide $\left[\mathrm{Pf}_{2} \mathrm{~N}\right]$; substituents: methyl $\left(-\mathrm{CH}_{3}\right)$, methylene $\left(-\mathrm{CH}_{2}-\right)$, dimethyl ammonium (-dmN).

The experimental data collected in this database were extracted for fitting the correlation equations and for generating the group contribution parameters. To evaluate the predictive performance of the proposed or employed group contribution models, training sets including nearly $70 \%$ of the datasets are used for correlation, and then the remaining datasets (i.e. test sets) not included in the training sets are used for prediction. The calculation results show that the proposed group contribution models allow accurate prediction of properties for a variety of ILs. A complete list of the studied properties of ILs is provided in the Supporting Information. Together with discussions on the prediction accuracy and reliability of the proposed group contribution methods, a brief analysis regarding the effect of temperature (and pressure) as well as of the IL molecular structure on the studied properties is also provided. Finally, we also present comparisons with some literature methods when this is possible.

\section{Results and discussion}

\subsection{Density}

As one of the most basic physical properties, density is required in the design of processes in material science and chemical engineering. Particularly, knowledge about density of ILs is essential since they are considered as promising alternatives for VOCs in applications in the chemical and biochemical industry. And the density data of ILs is needed in the design of product and process involving these compounds. However, given the huge number of ILs that can be combined by different kinds of functionalized cations attached to various substituents and anions, it is not possible to measure the density for all potential ILs. Therefore, the development of predictive methods for their density is of great importance.

To date, several methods for density estimation have been proposed for ILs in the form of empirical correlations ${ }^{25-29}$ or equation of state-based methods. ${ }^{30-34}$ However, these proposed models require volume and molecular information for the prediction of density. Therefore, simple group-contribution based methods that avoids this information is more attractive, especially in the integration of ILs in 
process design where the formulated problems are usually complex. As density is a temperaturepressure dependent property, some temperature-pressure related correlation must be developed. We have found that the form shown in Equation 1 is the best model with a minimum average absolute relative deviation (AARD) \% (defined as Eq.4).

$$
\rho=A_{\rho}+B_{\rho} \cdot T+C_{\rho} \cdot P
$$

where $\rho$ is the density in $\mathrm{kg} \cdot \mathrm{m}^{-3}, T$ is the temperature in $\mathrm{K}$ and $P$ is the pressure in MPa. $A_{\rho}, B_{\rho}$ and $C_{\rho}$ are estimated via a group contribution method according to

$$
A_{\rho}=\sum_{i=1}^{k} n_{i} a_{i, \rho} \quad B_{\rho}=\sum_{i=1}^{k} n_{i} b_{i, \rho} \quad C_{\rho}=\sum_{i=1}^{k} n_{i} c_{i, \rho}
$$

where $k$ is the total number of different groups in the molecule and $n_{i}$ denotes the number of groups of type $i$, and the group contribution parameters $a_{i, \rho}, b_{i, \rho}$ and $c_{i, \rho}$ can be obtained by fitting the available experimental data into Eq.1 using Eq.3 as the objective function.

$$
\begin{gathered}
\text { O.F. }=\sum_{i=1}^{N}\left|\left(\left(A_{\rho}+B_{\rho} \cdot T+C_{\rho} \cdot P\right)-\rho_{\text {exp }}\right) / \rho_{\text {exp }}\right|_{i} \\
A A R D(\%)=\frac{100 \%}{N} \sum_{i=1}^{N}\left|\left(\rho_{\text {cal }}-\rho_{\text {exp }}\right) / \rho_{\text {exp }}\right|_{i} \\
R D(\%)=100 \% \times\left(\rho_{\text {cal }}-\rho_{\text {exp }}\right) / \rho_{\text {exp }}
\end{gathered}
$$

where $N$ represents the number of experimental data points while subscripts exp and cal denote experimental and calculated properties, respectively.

A total set consist of 7360 density data points for 143 ILs covering 6 cations, 18 anions and 3 side groups in a wide range of temperature, 273.15-473.15K and pressure 0.1-250.7 MPa compiled in this work are analyzed and used. The uncertainty of these experimental data points is $0.25 \%$ with a maximum value of $2.27 \%$, indicating their reliability, and therefore no data is rejected.

Using Eq.3 as calculation model, the model parameters are fitted to 5039 experimental data for 90 ILs with an AARD (\%) of $0.43 \%$. Subsequently, this model is validated by a calculation of density for 53 ILs containing 2321 data points not included in the training set. The resulting AARD (\%) of prediction for the test set is $0.67 \%$ which shows a good prediction ability of the proposed group contribution models. Comparison between experimental and correlated/estimated densities of ILs and distributions of relative deviations between experimental data and model calculations (defined as Eq.5) for both training and test sets are presented, as shown in Figure 1.

To improve the reliability of the model parameters of the estimation method, all 7360 data points are employed as regression set and the corresponding group contribution parameters $a_{i . \rho}, b_{i . \rho}$ and $c_{i . \rho}$ are generated and provided in Table 1 . From the values of group contributions, different cations have similar contributions to the density of ILs. Temperature has a similar impact on the density of different families of ILs while the pressure contribution to the density of different families of ILs varies widely. As for most organic chemicals, the density of ILs increases with the decrease of temperature or the increase of pressure. 

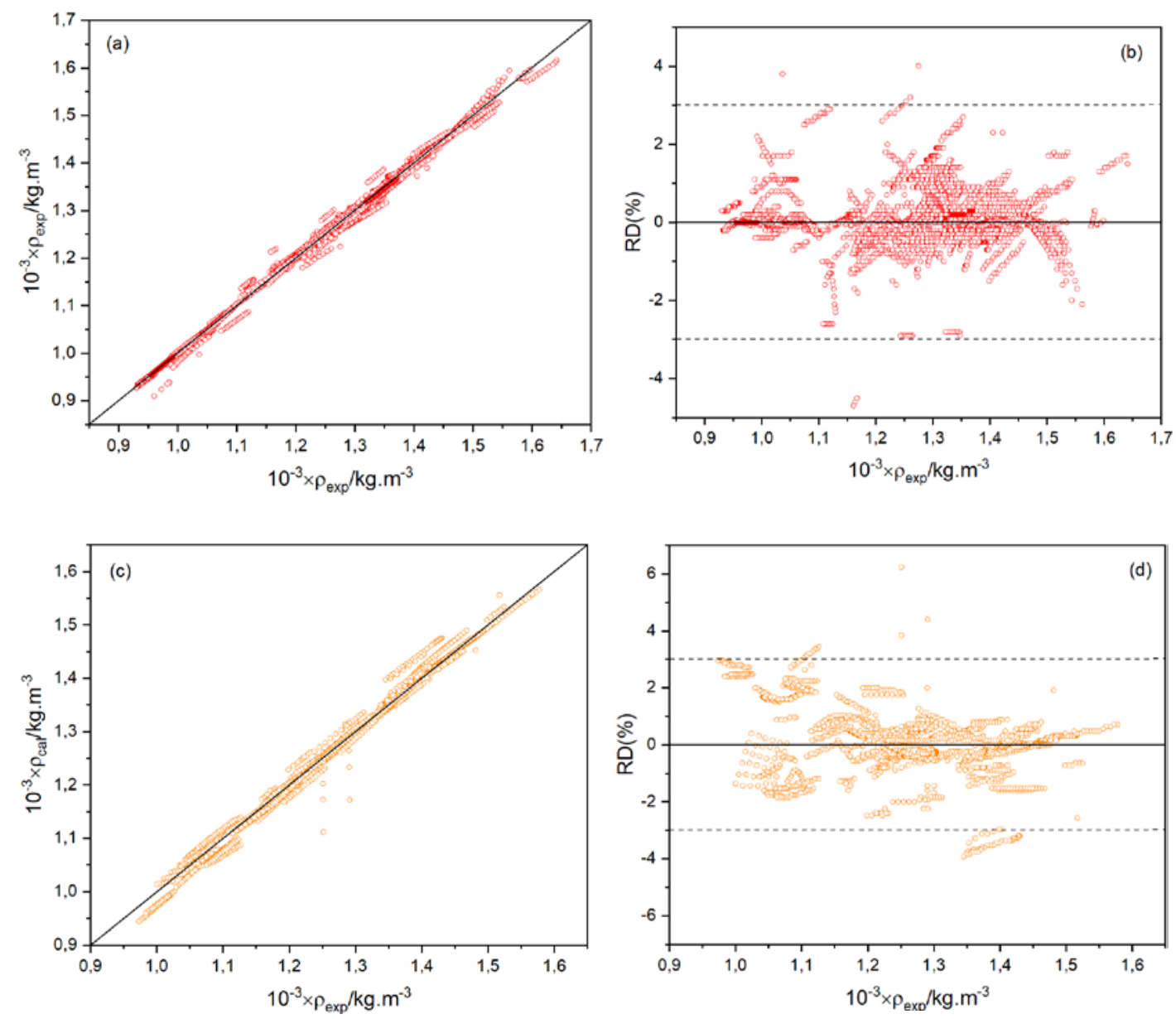

Figure 1. Plots of experimental versus calculated density for ILs and relative deviations between experimental and calculated data obtained by using Eq.1: (a) training set; (b) relative deviations for training set; (c) test set; (d) and relative deviations for test set.
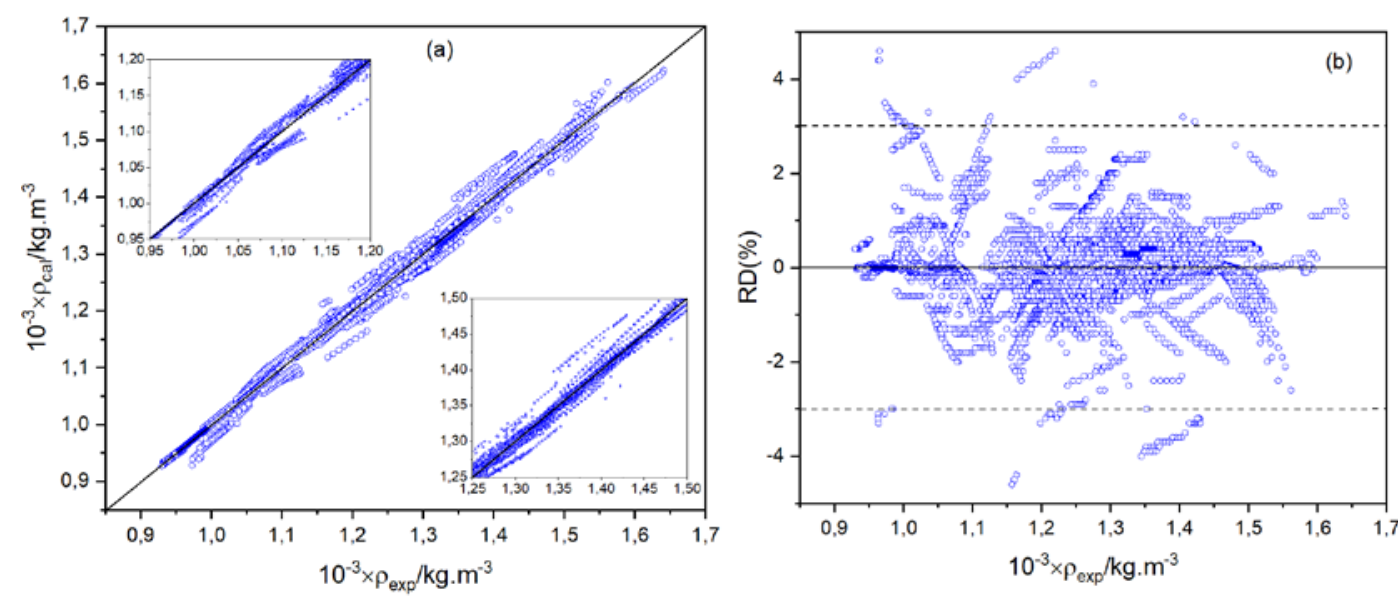

Figure 2. (a) Comparison between experimental and calculated density for all 7360 data points and (b) relative deviations between the experimental and calculated density as a function of experimental data of density used in Eq.1.

As shown in Figure 2, comparison between experimental and calculated densities of ILs and distributions of relative deviations between experimental data and model calculations of all data points 
are presented. The overall AARD (\%) of the studied ILs is $0.49 \%$ with a maximum deviation of $4.60 \%$. Among 7360 data points, $70.5 \%$ of the calculated densities are within relative deviation of $0.0-0.50 \%, 15.2 \%$ within $0.5-1.0 \%, 13.0 \%$ within $1.0-3.0 \%$, and only less than $1.2 \%$ of the calculated densities have deviation higher than $3.0 \%$.

Table 1: Generated group contribution parameters $a_{i . \rho}, b_{i . \rho}$ and $c_{i . \rho}$ for Eq.2 in the temperature range of 273.15-473.15K and pressure range of 0.1-250.7 MPa

\begin{tabular}{|c|c|c|c|}
\hline & $a_{i . \rho}\left(\mathrm{kg} . \mathrm{m}^{-3}\right)$ & $\mathrm{b}_{i . \rho}\left(\mathrm{kg} \cdot \mathrm{m}^{-3} \cdot \mathrm{K}^{-1}\right)$ & $c_{i . \rho}\left(\mathrm{kg} \cdot \mathrm{m}^{-3} \cdot \mathrm{Mpa}^{-1}\right)$ \\
\hline \multicolumn{4}{|l|}{ Substituents } \\
\hline$-\mathrm{CH}_{3}$ & -66.767 & 0.163 & -0.274 \\
\hline$-\mathrm{CH}_{2-}$ & -40.521 & 0.030 & -0.020 \\
\hline$-\mathrm{dmN}$ & -69.079 & 0.086 & 10.161 \\
\hline \multicolumn{4}{|l|}{ Cations } \\
\hline 1,3-dimethylimidazolium (+) & $1.099 \times 10^{3}$ & 3.956 & 6.687 \\
\hline 1,1-dimethylpyridinium (+) & $1.147 \times 10^{3}$ & 3.810 & 6.714 \\
\hline 1,1-dimethylpyrrolidinium (+) & $1.094 \times 10^{3}$ & 3.885 & 6.543 \\
\hline Tetramethyl ammonium $(+)$ & $1.106 \times 10^{3}$ & 3.952 & 19.553 \\
\hline Tetramethyl phosphonium (+) & $1.693 \times 10^{3}$ & 3.361 & 7.144 \\
\hline 1,1-dimethylpiperidinium (+) & $1.043 \times 10^{3}$ & 3.956 & 6.608 \\
\hline \multicolumn{4}{|l|}{ Anions } \\
\hline$\left[\mathrm{Tf}_{2} \mathrm{~N}\right]^{-}$ & 724.274 & -4.933 & -5.969 \\
\hline$\left[\mathrm{BF}_{4}\right]^{-}$ & 395.546 & -4.594 & -6.219 \\
\hline$\left[\mathrm{PF}_{6}\right]^{-}$ & 649.046 & -4.932 & -5.879 \\
\hline$\left[\mathrm{Cl}^{-}\right.$ & 335.520 & -4.745 & -6.368 \\
\hline$[\mathrm{Ac}]^{-}$ & 241.839 & -4.613 & -6.178 \\
\hline$\left[\mathrm{MeSO}_{4}\right]^{-}$ & 353.840 & -4.439 & -6.258 \\
\hline$\left[\mathrm{EtSO}_{4}\right]^{-}$ & 377.558 & -4.665 & 37.100 \\
\hline$\left[\mathrm{CF}_{3} \mathrm{SO}_{3}\right]^{-}$ & 598.051 & -4.938 & -6.057 \\
\hline$[\mathrm{Br}]^{-}$ & 560.637 & -4.763 & -6.051 \\
\hline$\left[\mathrm{CF}_{3} \mathrm{COO}\right]^{-}$ & 453.169 & -4.787 & 36.623 \\
\hline$\left[\mathrm{N}(\mathrm{CN})_{2}\right]^{-}$ & 261.113 & -4.659 & 35.582 \\
\hline$\left[\mathrm{C}(\mathrm{CN})_{3}\right]^{-}$ & 259.203 & -4.687 & -6.181 \\
\hline$\left[\mathrm{AlCl}_{4}\right]^{-}$ & 295.949 & -4.155 & 49.891 \\
\hline$\left[\mathrm{InCl}_{4}\right]^{-}$ & 861.751 & -5.046 & 138.233 \\
\hline$\left[\left(\mathrm{CH}_{3}\right)_{2} \mathrm{PO}_{4}\right]^{-}$ & 373.126 & -4.680 & -6.251 \\
\hline$\left[\mathrm{FeCl}_{4}\right]^{-}$ & 609.170 & -4.827 & 54.561 \\
\hline$\left[\mathrm{GaCl}_{4}\right]^{-}$ & 161.394 & -3.189 & 25.417 \\
\hline$\left[\mathrm{Pf}_{2} \mathrm{~N}\right]^{-}$ & 116.042 & -2.676 & -7.299 \\
\hline
\end{tabular}

\subsection{Heat capacity}

Heat capacity is an important thermophysical and thermodynamic property that characterizes a compound and it can also provide information on temperature of phase transitions and reaction equilibria. ${ }^{35}$ A satisfactory knowledge of heat capacity is necessary to understand the structural changes of a compound. The information of heat capacity is required in many engineering calculations like entropy, enthalpy and changes in reaction enthalpies with temperature.

Unlike the density of ILs, their heat capacity varies widely with different structures. Since available experimental heat capacities of ILs are limited to a few families of ILs, alternative methods should be established to overcome this limitation. 
There have been a few literature studies in this respect. Gardas and Coutinho proposed a temperature dependent correlation equation (Eq.6) that can predict the heat capacity of ILs very well. ${ }^{35}$ However, only 3 cations, 6 anions and 3 side groups were considered in their work. In the current work, this method is extended to more families of ILs:

$$
C_{p L}=R\left(A_{C_{p L}}+B_{C_{p L}}\left(\frac{T}{100}\right)+D_{C_{p L}}\left(\frac{T}{100}\right)^{2}\right)
$$

where $C_{p L}$ represents the heat capacity in J.mol-1. $\mathrm{K}^{-1}, T$ is the absolute temperature in $\mathrm{K}$ and $R$ is the gas constant $\left(8.3145 \mathrm{~J} \cdot \mathrm{mol}^{-1} \cdot \mathrm{K}^{-1}\right) . A_{C_{p L}}, B_{C_{p L}}$ and $D_{C_{p L}}$ are parameters that are estimated from group contributions using Eq.7.

$$
A_{C_{p L}}=\sum_{i=1}^{k} n_{i} a_{i, C_{p L}} \quad B_{C_{p L}}=\sum_{i=1}^{k} n_{i} b_{i, C_{p L}} \quad D_{C_{p L}}=\sum_{i=1}^{k} n_{i} d_{i, C_{p L}}
$$

where $n_{i}$ is the number of groups of type $i$ and $k$ represents the total number of different groups in the IL molecule. The group contributions parameters $a_{i, C_{p L}}, b_{i, C_{p L}}$ and $d_{i, C_{p L}}$ are obtained by fitting the available experimental data in Eq.6 using Eq.8 as the objective function.

$$
O . F .=\sum_{i=1}^{N}\left|\left(R\left(A_{C_{p L}}+B_{C_{p L}}\left(\frac{T}{100}\right)+D_{C_{p L}}\left(\frac{T}{100}\right)^{2}\right)-C_{p L} \exp \right) / C_{p L_{e x p}}\right|_{i}
$$

A number of 3304 heat capacity data points for 61 ILs including 6 cations, 14 anions and 3 side groups in a wide range of temperature, $189.66-524.87 \mathrm{~K}$ collected in the database are studied. These experimental data points have an uncertainty of $2.27 \%$ and a maximum of $10.23 \%$. Among these data points, a training set including 2391 experimental data for 44 ILs is used for the correlation of this model and an AARD (\%) of $0.39 \%$ is obtained. Then, this model is evaluated by the prediction of heat capacity for the remaining 913 data points for 17 ILs. The resulting AARD (\%) of prediction is $0.62 \%$ which shows that this group contribution model can estimate the heat capacity of studied ILs with sufficient accuracy. As shown in Figure 3, the calculation results are illustrated as the comparison between experimental and correlated/predicted heat capacities of ILs. Meanwhile, distributions of relative deviations between experimental data and model calculations for both correlation and prediction sets are illustrated as well. In most cases, the deviations of predicted heat capacities are less than the corresponding experimental uncertainties.

Table 1 shows the calculation results of group contribution parameters $a_{i . c_{p L}}, b_{i . C_{p L}}$ and $c_{i . C_{p L}}$ using all 3304 data points as correlation set. Generally, the heat capacity of ILs increases with increasing temperature. For ILs having a common cation and anion, the heat capacity increases when the number of $-\mathrm{CH}_{3}$ decreases or the number of $-\mathrm{CH}_{2}$ - and $-\mathrm{dmN}$ increase on the cation. The relationship between the calculated and the experimental heat capacity is presented in Figure 4a, an overall AARD of $0.43 \%$ is observed for this correlation. The relationship between $\mathrm{RD}(\%)$ and experimental heat capacity is also given (see Figure $4 \mathrm{~b}$ ). From these $72.0 \%$ of the correlated heat capacities are within relative deviation of $0.0-0.40 \%, 16.4 \%$ within $0.4-1.00 \%, 11.4 \%$ within $1.0-3.0 \%$, and only $0.2 \%$ of the calculated heat capacities have larger than $3.0 \%$ deviation. The maximum relative deviation is $4.6 \%$ observed for 1-propylpyridinium hexafluorophosphate $\left(\left[\mathrm{C}_{3} \mathrm{Py}\right]\left[\mathrm{PF}_{6}\right]\right)$ at $380 \mathrm{~K}$. 

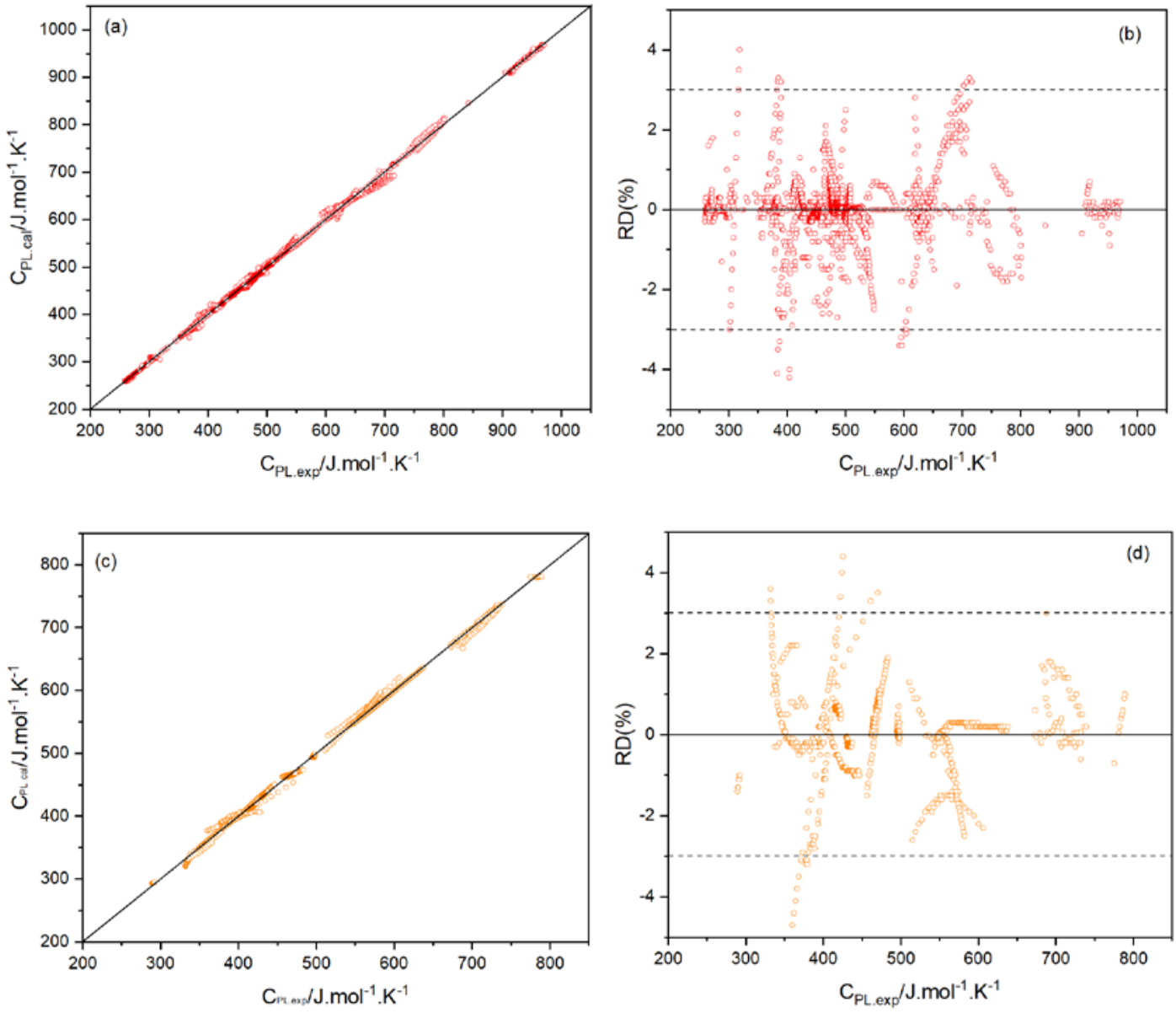

Figure 3. Plots of experimental versus calculated heat capacity for ILs and relative deviations between experimental and calculated data obtained by using Eq.6: (a) training set; (b) relative deviations for training set; (c) test set; (d) and relative deviations for test set.
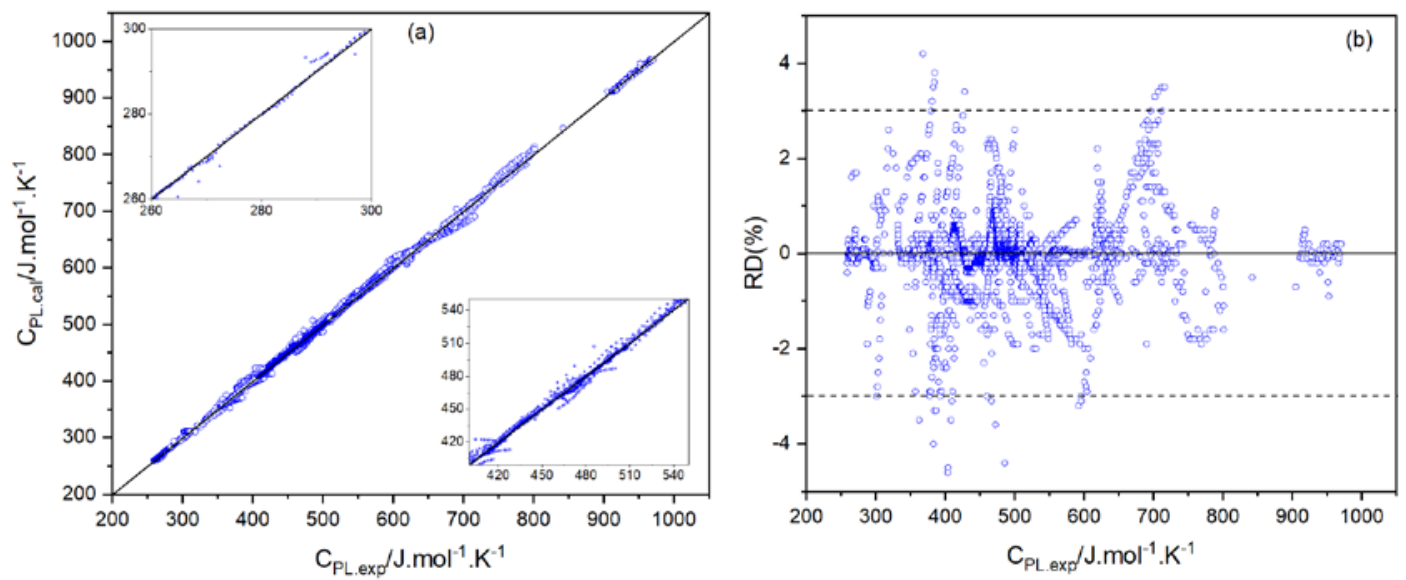

Figure 4. (a) Comparison between experimental and calculated heat capacity for all 3304 data points and (b) relative deviations between the experimental and calculated heat capacity as a function of experimental data of heat capacity used in Eq.6. 
Table 2: Generated group contribution parameters $a_{i, C_{p L}}, b_{i, C_{p L}}$ and $d_{i, C_{p L}}$ for Eq.6 in the temperature range of $189.66-524.87 \mathrm{~K}$

\begin{tabular}{|c|c|c|c|}
\hline & $a_{i . C_{p L}}$ & $b_{i . c_{p L}}\left(\mathrm{~K}^{-1}\right)$ & $d_{i . C_{p L}}\left(\mathrm{~K}^{-2}\right)$ \\
\hline \multicolumn{4}{|l|}{ Substituents } \\
\hline$-\mathrm{CH}_{3}$ & 156.626 & -112.005 & 19.275 \\
\hline$-\mathrm{CH}_{2-}$ & 5.347 & -1.36 & 0.295 \\
\hline$-\mathrm{dmN}$ & 26.725 & -13.606 & 2.422 \\
\hline \multicolumn{4}{|l|}{ Cations } \\
\hline 1,3-dimethylimidazolium (+) & 22.446 & -22.585 & -2.585 \\
\hline 1-methylpyridinium (+) & 2.976 & -6.385 & -5.477 \\
\hline 1,1-dimethylpyrrolidinium (+) & 19.489 & -20.521 & -2.749 \\
\hline Tetramethyl ammonium (+) & 106.569 & -71.423 & 4.062 \\
\hline Trihexyl tetradecyl phosphonium (+) & -45.847 & 41.346 & -9.449 \\
\hline 1,1-dimethylpiperidinium (+) & 23.984 & -19.567 & -2.873 \\
\hline \multicolumn{4}{|l|}{ Anions } \\
\hline$\left[\mathrm{Tf}_{2} \mathrm{~N}\right]^{-}$ & 13.795 & 30.684 & 2.226 \\
\hline$\left[\mathrm{BF}_{4}\right]^{-}$ & -25.69 & 25.092 & 2.86 \\
\hline$\left[\mathrm{PF}_{6}\right]^{-}$ & 0.00 & 42.574 & 0.432 \\
\hline$[\mathrm{Cl}]^{-}$ & 2.816 & 19.246 & 3.80 \\
\hline$[\mathrm{Ac}]^{-}$ & 8.11 & 19.499 & 4.015 \\
\hline$\left[\mathrm{MeSO}_{4}\right]^{-}$ & -54.863 & 59.355 & -2.407 \\
\hline$\left[\mathrm{EtSO}_{4}\right]^{-}$ & 16.916 & 20.05 & 3.752 \\
\hline$\left[\mathrm{CF}_{3} \mathrm{SO}_{3}\right]^{-}$ & -7.10 & 36.111 & 1.089 \\
\hline$[\mathrm{Br}]^{-}$ & -0.171 & 21.957 & 3.161 \\
\hline$\left[\mathrm{CF}_{3} \mathrm{COO}\right]^{-}$ & 2.364 & 26.686 & 2.609 \\
\hline$\left[\mathrm{N}(\mathrm{CN})_{2}\right]^{-}$ & 5.939 & 22.349 & 3.239 \\
\hline$\left[\mathrm{C}(\mathrm{CN})_{3}\right]^{-}$ & 45.515 & 0.00 & 6.749 \\
\hline$\left[\left(\mathrm{CH}_{3}\right)_{2} \mathrm{PO}_{4}\right]^{-}$ & -444.627 & 299.913 & -39.109 \\
\hline$\left[\mathrm{FeCl}_{4}\right]^{-}$ & -16.985 & 42.172 & 0.00 \\
\hline
\end{tabular}

\subsection{Viscosity}

Viscosity is the property of a fluid which opposes the relative motion between two surfaces of the fluid. A good knowledge of the viscosity of fluids and their mixtures is important for the design of process piping, heat-transfer equipment, stripping columns, liquid-liquid extractors, reactors, distillation columns, crystallization equipment, and other units used in various oil, chemical, paint and food industry. The information on viscosity is indispensable in the process design and is also required for process simulation and optimization. ${ }^{36}$

Compared to the viscosities of conventional organic solvents, viscosities of ILs are generally much higher. Experimental data for this property are still scarce and restricted to a few families of ILs, therefore, empirical or theoretical predicted methods are necessary.

Some predictive methods have been proposed for estimating viscosities of ILs based on the OrrickErbar-type approach, ${ }^{37}$ the Vogel-Tammann-Fulcher (VTF) equation, ${ }^{36}$ then a QSPR correlation was developed for two families of ILs, dicyanamide and tributyl-(3-amino-propyl) phosphonium. ${ }^{38}$

However, these methods either require density information for the estimation of viscosity or are limited to a small families of ILs. To overcome these restrictions, an easy method covering more 
families of ILs is necessary. For this purpose, we have developed a new correlation equation (Eq.9) which, moreover, shows improvement in the viscosity prediction of ILs compared to literature

$$
\ln \frac{\eta}{R_{0 \eta}}=A_{\eta}+B_{\eta} \frac{100}{T}+D_{\eta}\left(\frac{100}{T}\right)^{2}
$$

where $\eta$ is the viscosity in Pa.s and $T$ is the temperature in $\mathrm{K} . R_{0 \eta}$ is an adjustable parameter, also expressed in Pa.s. $A_{\eta}, B_{\eta}$ and $C_{\eta}$ are estimated by a group contribution method, shown in Eq.10.

$$
A_{\eta}=\sum_{i=1}^{k} n_{i} a_{i, \eta} \quad B_{\eta}=\sum_{i=1}^{k} n_{i} b_{i, \eta} \quad D_{\eta}=\sum_{i=1}^{k} n_{i} d_{i, \eta}
$$

where $k$ is the total number of different groups in the molecule and $n_{i}$ is the number of groups of type $i$. The group contributions $a_{i, \eta}, b_{i, \eta}$ and $d_{i, \eta}$ are generated by fitting the available experimental data into Eq.9 using Eq.11 as the objective function.

$$
\text { O.F. }=\sum_{i=1}^{N}\left|\left(\exp \left(A_{\eta}+B_{\eta} \frac{100}{T}+D_{\eta}\left(\frac{100}{T}\right)^{2}\right) * R_{0 \eta}-\eta_{\exp }\right) / \eta_{\exp }\right|_{i}
$$

For this property, 1090 experimental data points for 76 ILs covering 8 cation cores, 16 anions and 3 side groups in a wide range of temperature, $278.0-408.15 \mathrm{~K}$ were extracted from the database. The uncertainty of these experimental viscosity data is $3.69 \%$ with a maximum value of $25.15 \%$. A training set consists of 778 data points for 56 ILs is used to correlate the proposed group contribution model (Eq.9) with an AARD (\%) of 3.36\%. To evaluate this model, the generated group contribution parameters are employed to predict the viscosity of 20 ILs containing 312 data points not included in the training set. The resulting AARD (\%) of prediction is 5.63\%, showing that the experimental viscosity can be described well by the proposed model. For both training and test sets, comparison between experimental and calculated viscosities of ILs and their corresponding distributions of relative deviations between experimental data and model calculations are presented, as shown in Figure 5.

For all substances (76 ILs) the AARD (\%) is 3.58\%, and the corresponding optimum value of $R_{0 \eta}$ is found to be 14.877 Pa.s. As presented in Figure 6, among all 1090 data points, $67.2 \%$ of the calculated viscosities are within relative deviation of $0.00-3.0 \%$, 18.5\% within $3.0-8.0 \%$, $12.5 \%$ within 8.0 $20.0 \%$, and only $1.8 \%$ of the calculated viscosities having larger than $20.0 \%$ deviation. The maximum relative deviation is $27.7 \%$ observed for 1-butyl-3-methylimidazolium trifluoroacetate ([C $\left.\left.\mathrm{C}_{4} \mathrm{mIm}\right]\left[\mathrm{CF}_{3} \mathrm{COO}\right]\right)$ at $313 \mathrm{~K}$.

The generated group contribution parameters $a_{i, \eta}, b_{i, \eta}$ and $d_{i, \eta}$ are provided in Table 3. Since where $-\mathrm{CH}_{3}$ attached directly to the cation or not has a great influence on the viscosity of ILs containing imidazolium, in order to obtain a better correlation performance of the estimated model for the viscosity of some ILs, we divide imidazolium cation cores into 1,3-dimethylimidazolium (+) and 1,2,3-trimethylimidazolium $(+)$. Usually, the viscosity of ILs decreases with an increase in temperature while it increases with the increase of the side chain length on the cation. 

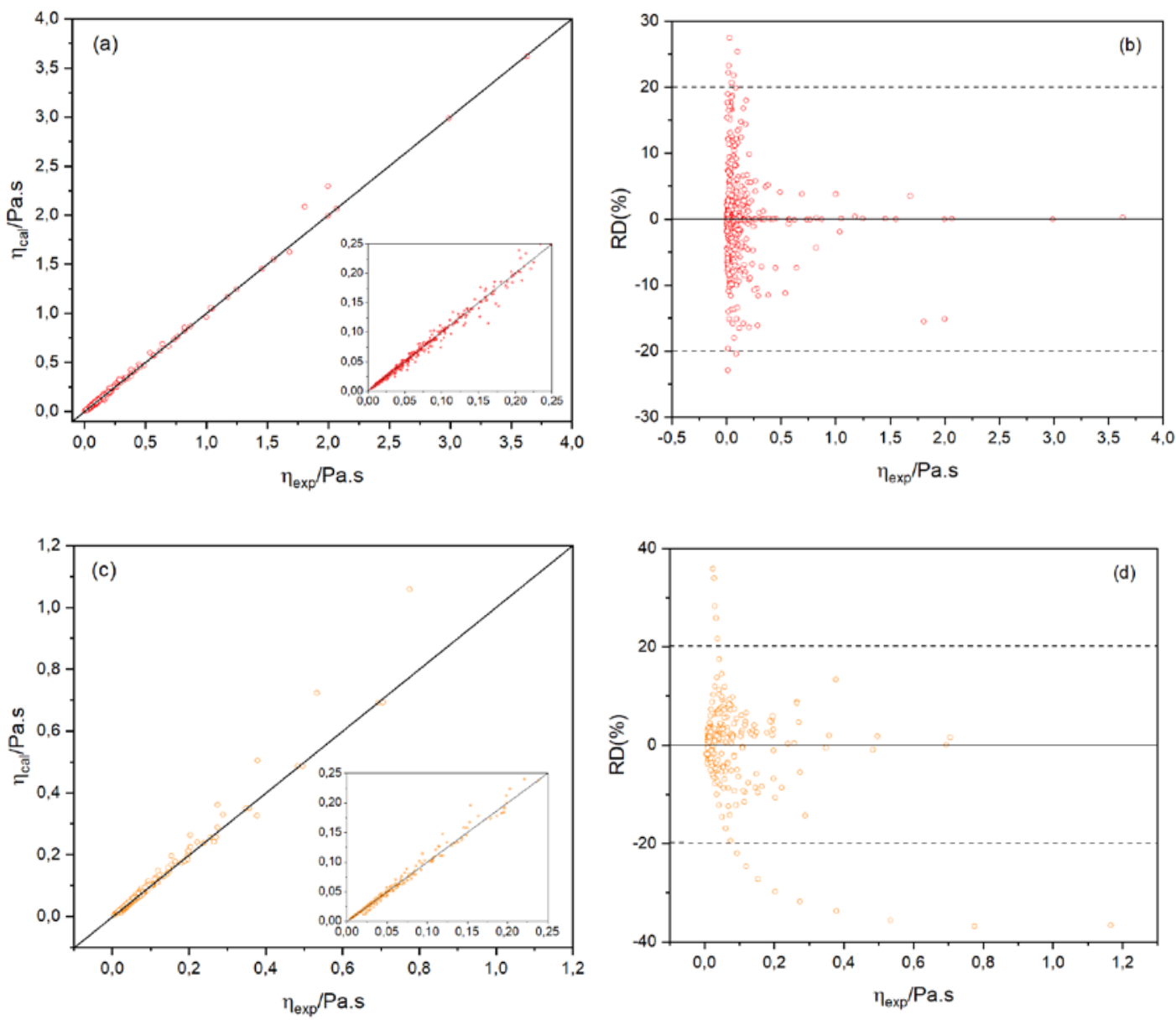

Figure 5. Plots of experimental versus calculated viscosity for ILs and relative deviations between experimental and calculated data obtained by using Eq.9: (a) training set; (b) relative deviations for training set; (c) test set; (d) and relative deviations for test set.
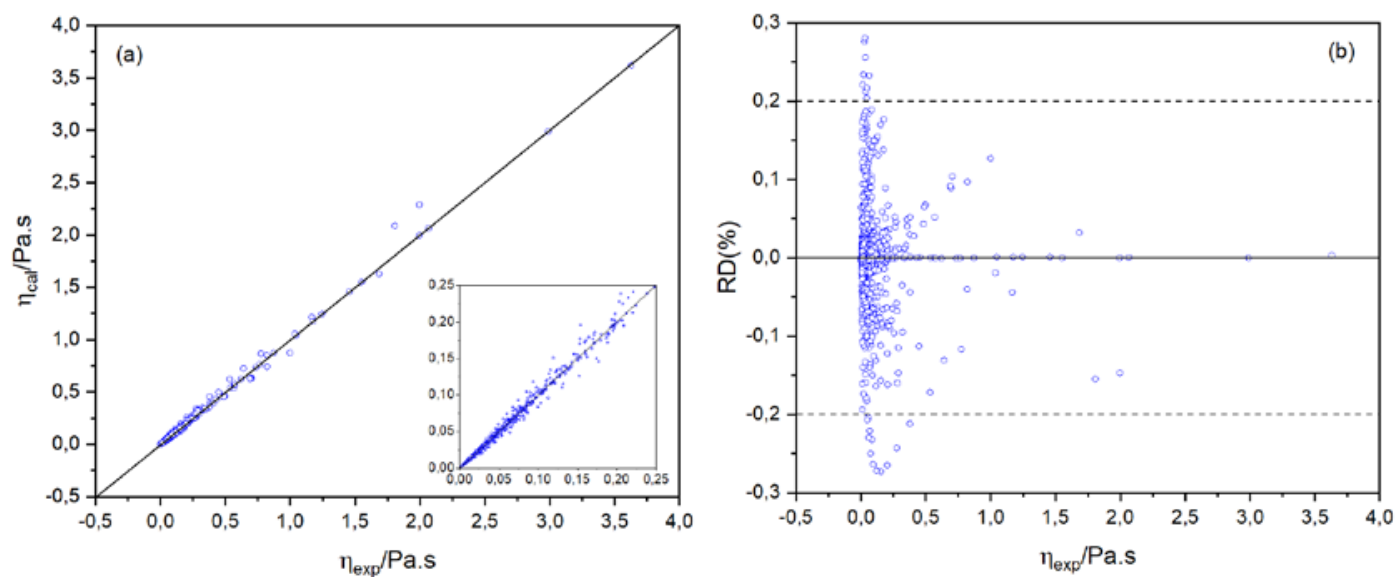

Figure 6. (a) Comparison between experimental and calculated viscosity for all 1090 data points and (b) relative deviations between the experimental and calculated viscosity as a function of experimental data of heat capacity used in Eq.9. 
Table 3: Generated group contribution parameters $a_{i, \eta}, b_{i, \eta}$ and $d_{i, \eta}$ for Eq.10 in the temperature range of $278-408.15 \mathrm{~K}$

\begin{tabular}{|c|c|c|c|}
\hline & $a_{i . \eta}$ & $b_{i . \eta}(\mathrm{K})$ & $d_{i . \eta}\left(\mathrm{K}^{2}\right)$ \\
\hline \multicolumn{4}{|l|}{ Substituents } \\
\hline$-\mathrm{CH}_{3}$ & 0.933 & -7.113 & 13.456 \\
\hline$-\mathrm{CH}_{2^{-}}$ & -0.346 & 1.460 & 0.076 \\
\hline$-\mathrm{dmN}$ & 5.319 & -35.574 & 61.498 \\
\hline \multicolumn{4}{|l|}{ Cations } \\
\hline 1,3-dimethylimidazolium (+) & 1.811 & -12.885 & 68.642 \\
\hline 1,2,3-trimethylimidazolium (+) & -1.260 & 3.516 & 53.002 \\
\hline 1-methylpyridinium (+) & 3.710 & -26.702 & 94.864 \\
\hline 1,1-dimethylpyrrolidinium (+) & 0.106 & 0.605 & 45.537 \\
\hline Tetramethyl ammonium $(+)$ & 6.829 & -48.328 & 134.296 \\
\hline Tetramethyl phosphonium (+) & -0.650 & 4.068 & 38.609 \\
\hline Trihexyl tetradecyl phosphonium (+) & 0.275 & -9.725 & 94.069 \\
\hline 1,1-dimethylpiperidinium (+) & 7.069 & -52.878 & 152.84 \\
\hline \multicolumn{4}{|l|}{ Anions } \\
\hline$\left[\mathrm{Tf}_{2} \mathrm{~N}\right]^{-}$ & -8.316 & -16.355 & 21.492 \\
\hline$\left[\mathrm{BF}_{4}\right]^{-}$ & -5.882 & -36.536 & 67.261 \\
\hline$\left[\mathrm{PF}_{6}\right]^{-}$ & -15.446 & 22.093 & -12.529 \\
\hline$[\mathrm{Cl}]^{-}$ & -95.536 & 507.333 & -750.412 \\
\hline$[\mathrm{Ac}]^{-}$ & 7.889 & -141.685 & 261.178 \\
\hline$\left[\mathrm{MeSO}_{4}\right]^{-}$ & -8.035 & -20.293 & 37.956 \\
\hline$\left[\mathrm{EtSO}_{4}\right]^{-}$ & -6.103 & -34.046 & 63.386 \\
\hline$\left[\mathrm{CF}_{3} \mathrm{SO}_{3}\right]^{-}$ & -4.313 & -38.135 & 52.575 \\
\hline$[\mathrm{Br}]^{-}$ & -8.849 & -16.287 & 45.433 \\
\hline$\left[\mathrm{CF}_{3} \mathrm{COO}\right]^{-}$ & -2.852 & -50.171 & 72.712 \\
\hline$\left[\mathrm{N}(\mathrm{CN})_{2}\right]^{-}$ & -7.697 & -20.126 & 22.490 \\
\hline$\left[\mathrm{C}(\mathrm{CN})_{3}\right]^{-}$ & -5.616 & -36.359 & 52.103 \\
\hline$\left[\mathrm{AlCl}_{4}\right]^{-}$ & -9.494 & -5.058 & -7.965 \\
\hline$\left[\left(\mathrm{CH}_{3}\right)_{2} \mathrm{PO}_{4}\right]^{-}$ & -6.464 & -32.730 & 71.381 \\
\hline$\left[\mathrm{FeCl}_{4}\right]^{-}$ & -6.766 & -25.374 & 33.078 \\
\hline$\left[\mathrm{Pf}_{2} \mathrm{~N}\right]^{-}$ & -6.092 & -35.181 & 65.466 \\
\hline
\end{tabular}

\subsection{Surface tension}

The surface tension is an important property in many fields like reactor engineering, chemical and biochemical engineering, and it also relates to environmental problems. ${ }^{39,40}$ The increasing interest in ILs requires a better knowledge of their surface properties, for example, in the IL-based extraction or multiphasic homogeneous catalytic reactions ${ }^{41}$ where processes occur at the interface between ILs and other solvents (aqueous or organic phase) that require the information of surface properties. Considering the experimental surface tension is only available for a small number of well-known ILs, the development of estimation methods for this property of ILs is needed.

Gardas and Coutinho proposed a QSPR correlation based on parachors which can be used together with a prediction method for the densities to predict the surface tensions of ILs. ${ }^{42}$ However, this QSPR correlation requires information of both parachors and density. Therefore, an easier to use method with higher prediction accuracy may be more attractive. In this study, we propose a new correlation 
equation (Eq.12) for the prediction of the surface tension of ILs, where numerous experimental data of surface tension from various families of ILs are used.

$$
\ln \sigma=A_{\sigma}+B_{\sigma}\left(\frac{T}{100}\right)+D_{\sigma}\left(\frac{T}{100}\right)^{2}
$$

where $\sigma$ is the viscosity in N.m ${ }^{-1}$ and $T$ is the temperature in K. Parameters $A_{\sigma}, B_{\sigma}$ and $D_{\sigma}$ are calculated by a group contribution method according to

$$
A_{\sigma}=\sum_{i=1}^{k} n_{i} a_{i, \sigma} \quad B_{\sigma}=\sum_{i=1}^{k} n_{i} b_{i, \sigma} \quad D_{\sigma}=\sum_{i=1}^{k} n_{i} d_{i, \sigma}
$$

where $k$ is the total number of different groups in the molecule while $n_{i}$ denotes the number of groups of type $i$, and the group contributions $a_{i, \sigma}, b_{i, \sigma}$ and $d_{i, \sigma}$ are obtained by fitting the collected experimental surface tension data into Eq.12 while using Eq.14 as the objective function.

$$
\text { O.F. }=\sum_{i=1}^{N}\left|\left(\exp \left(A_{\sigma}+B_{\sigma} \frac{100}{T}+D_{\sigma}\left(\frac{100}{T}\right)^{2}\right)-\sigma_{\text {exp }}\right) / \sigma_{\text {exp }}\right|_{i}
$$

In this work, 1365 surface tension data points for 102 ILs involving 6 cation cores, 18 anions and 2 side groups in a wide range of temperature, 262.89-393.0 K are collected. These experimental data points have an uncertainty of $2.16 \%$ and a maximum of $20.65 \%$ is observed. Using Eq.12 as calculation model, a training set including 952 experimental data for 72 ILs and a test set containing 413 experimental data for 30 ILs not considered in the training set are used for correlation and prediction of surface tension, respectively. The AARD (\%) of correlation set is $2.87 \%$ and the AARD (\%) of prediction set is $4.71 \%$, indicating a good predictive capability of the proposed group contribution model. As shown in Figure 7, the calculation results are presented as the comparison between experimental and correlated/predicted surface tension of ILs, while distributions of relative deviations between experimental data and model calculations for both correlation and prediction sets are presented as well.

As with the viscosity, the surface tension of ILs decreases with increasing temperature, but it increases with the increase of the side chain length on the cation. Using all 1365 data points as correlation set, the group contribution parameters $a_{i, \sigma}, b_{i, \sigma}$ and $d_{i, \sigma}$ are achieved and given in Table 4 .

As shown in Figure 8a, calculated surface tensions are in good agreement with experimental data of surface tension collected from literature. Figure 8b shows the relationship between RD (\%) and experimental data of surface tension for all correlated 1365 data points. The overall AARD (\%) is $3.10 \%$. From these $50.3 \%$ of the correlated surface tensions are within relative deviation of $0.0-2.0 \%$, $19.0 \%$ within $2.0-4.0 \%, 23.8 \%$ within $4.0-8.0 \%$, and only $6.9 \%$ of the calculated surface tensions having larger than $8.0 \%$ deviation. The maximum relative deviation is $22.1 \%$ observed for trihexyl tetradecyl phosphonium bis(trifluoromethylsulfonyl)imide $\left([6,6,6,14 \mathrm{Ph}]\left[\mathrm{Tf}_{2} \mathrm{~N}\right]\right)$ at $318.2 \mathrm{~K}$. 

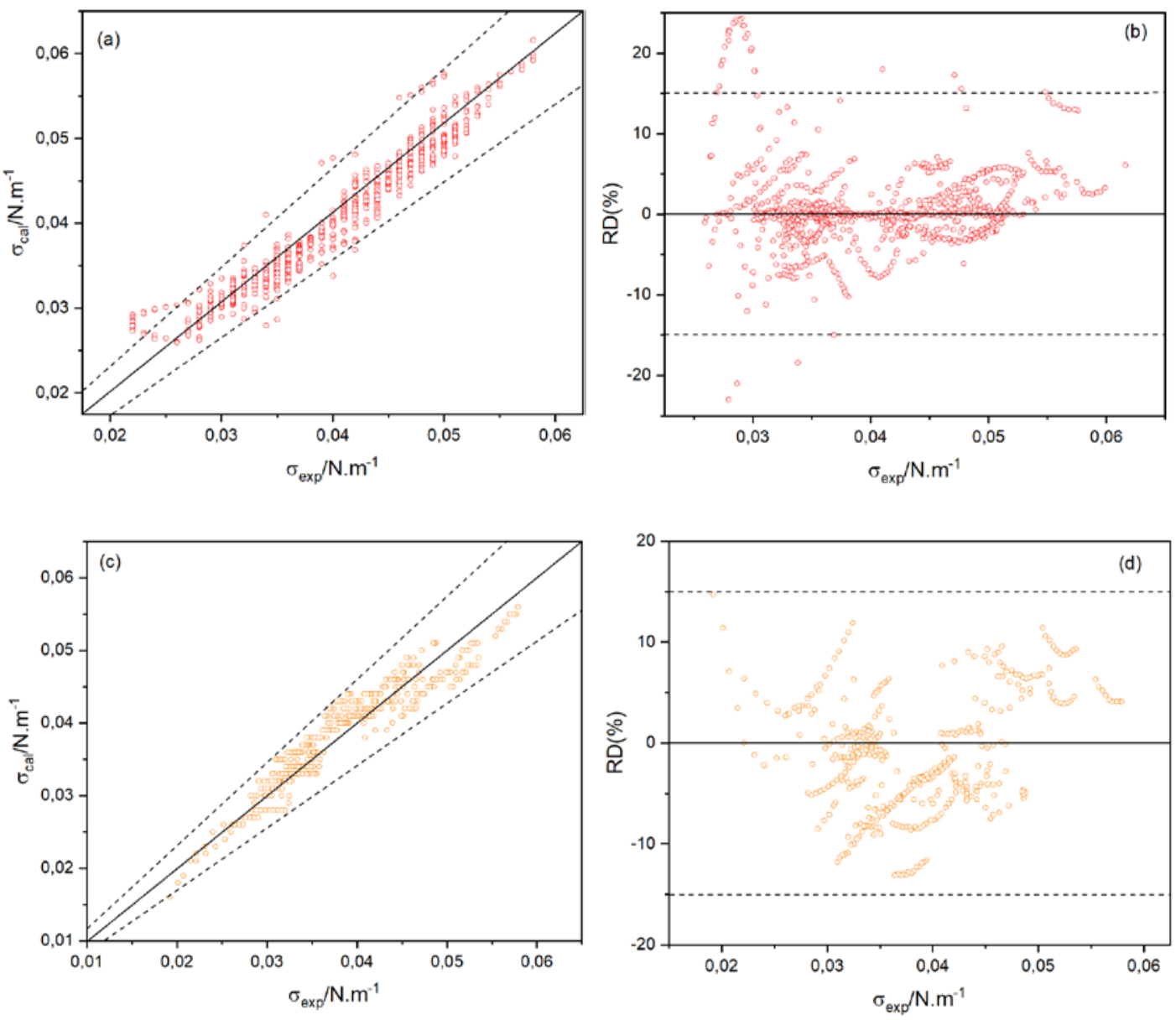

Figure 7. Plots of experimental versus calculated surface tension for ILs and relative deviations between experimental and calculated data obtained by using Eq.12: (a) training set; (b) relative deviations for training set; (c) test set; (d) and relative deviations for test set. Dashed lines correspond to $\pm 15 \%$ of relative deviation.
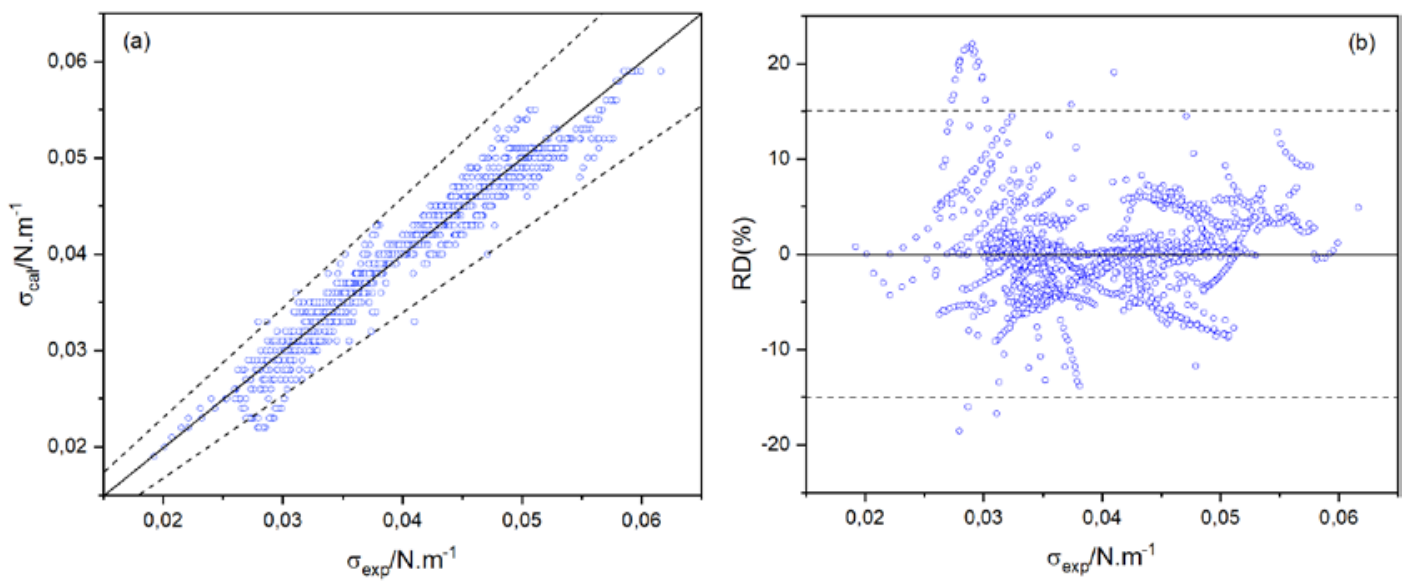

Figure 8. (a) Comparison between experimental and calculated surface tension for all 1365 data points and (b) relative deviations between the experimental and calculated surface tension as a function of experimental data of surface tension used in Eq.12. Dashed lines correspond to $\pm 15 \%$ of relative deviation. 
Table 4: Generated group contribution parameters $a_{i, \sigma}, b_{i, \sigma}$ and $d_{i, \sigma}$ for Eq.13 in the temperature range of 262.89-393 K

\begin{tabular}{|c|c|c|c|}
\hline & $a_{i . \sigma}\left(\mathrm{N} \cdot \mathrm{m}^{-1}\right)$ & $b_{i . \sigma}\left(\mathrm{N} \cdot \mathrm{m}^{-1} \cdot \mathrm{K}^{-1}\right)$ & $d_{i . \sigma}\left(\mathrm{N} \cdot \mathrm{m}^{-1} \cdot \mathrm{K}^{-2}\right)$ \\
\hline \multicolumn{4}{|l|}{ Substituents } \\
\hline$-\mathrm{CH}_{3}$ & 2.583 & -1.734 & 0.286 \\
\hline$-\mathrm{CH}_{2^{-}}$ & -0.195 & 0.079 & -0.01 \\
\hline \multicolumn{4}{|l|}{ Cations } \\
\hline 1,3-dimethylimidazolium (+) & -2.431 & 0.28 & -0.257 \\
\hline 1-methylpyridinium (+) & -4.906 & 1.928 & -0.525 \\
\hline 1,1-dimethylpyrrolidinium (+) & -1.882 & -0.092 & -0.19 \\
\hline Tetramethyl ammonium (+) & -1.672 & 0.096 & -0.249 \\
\hline Trihexyl tetradecyl phosphonium (+) & 10.822 & -8.234 & 1.061 \\
\hline 1,1-dimethylpiperidinium (+) & -2.199 & 0.186 & -0.247 \\
\hline \multicolumn{4}{|l|}{ Anions } \\
\hline$\left[\mathrm{Tf}_{2} \mathrm{~N}\right]^{-}$ & -0.247 & -0.511 & 0.268 \\
\hline$\left[\mathrm{BF}_{4}\right]^{-}$ & -1.161 & 0.327 & 0.127 \\
\hline$\left[\mathrm{PF}_{6}\right]^{-}$ & 0.34 & -0.683 & 0.291 \\
\hline$[\mathrm{Cl}]^{-}$ & 0.704 & -0.838 & 0.31 \\
\hline$[\mathrm{Ac}]^{-}$ & 5.26 & -3.763 & 0.752 \\
\hline$\left[\mathrm{MeSO}_{4}\right]^{-}$ & -4.272 & 2.336 & -0.198 \\
\hline$\left[\mathrm{EtSO}_{4}\right]^{-}$ & 1.762 & -1.692 & 0.463 \\
\hline$\left[\mathrm{CF}_{3} \mathrm{SO}_{3}\right]^{-}$ & 0.818 & -1.087 & 0.352 \\
\hline$[\mathrm{Br}]^{-}$ & -12.018 & 7.002 & -0.905 \\
\hline$\left[\mathrm{CF}_{3} \mathrm{COO}\right]^{-}$ & -0.049 & -0.568 & 0.269 \\
\hline$\left[\mathrm{N}(\mathrm{CN})_{2}\right]^{-}$ & -0.793 & 0.089 & 0.177 \\
\hline$\left[\mathrm{C}(\mathrm{CN})_{3}\right]^{-}$ & 0.06 & -0.385 & 0.235 \\
\hline$\left[\mathrm{AlCl}_{4}\right]^{-}$ & 0.202 & -0.561 & 0.27 \\
\hline$\left[\mathrm{InCl}_{4}\right]^{-}$ & 1.211 & -1.207 & 0.375 \\
\hline$\left[\left(\mathrm{CH}_{3}\right)_{2} \mathrm{PO}_{4}\right]^{-}$ & -0.396 & -0.128 & 0.181 \\
\hline$\left[\mathrm{FeCl}_{4}\right]^{-}$ & 1.34 & -1.32 & 0.39 \\
\hline$\left[\mathrm{GaCl}_{2}\right]^{-}$ & 0.349 & -0.667 & 0.29 \\
\hline$\left[\mathrm{Pf}_{2} \mathrm{~N}\right]^{-}$ & -0.005 & -0.015 & 0.066 \\
\hline
\end{tabular}

\subsection{Melting point}

The Melting point of a substance is a basic physical property that describes the temperature at which it changes state from solid to liquid at atmospheric pressure. As for the conventional organic chemicals, a detailed information of melting point of ILs is essential in the products and processes design involving these compounds. Particularly, the melting point of ILs varies widely with their structure (cation, anion and substituents) ${ }^{43}$

The QSPR and group contribution methods are two usual methods applied to correlate and predict the melting point of ILs.$^{44}$ Katritzky ${ }^{45}$ and Carrera ${ }^{46}$ proposed QSPR models for the melting point based on the same experimental data of 126 structurally diverse pyridinium bromides. Then, Lazzús presented a simple group contribution method to estimate the melting points of several families of ILs, which shows that the group contribution method is an excellent alternative for estimating the melting point of diverse ILs. ${ }^{47}$ In this work, a new group contribution-based correlation (Eq.15) is proposed for estimating the melting point of ILs.

$$
T_{m}=\sum_{\mathrm{c}=1}^{k_{\mathrm{c}}} n_{\mathrm{c}} t_{\mathrm{c}}+\sum_{\mathrm{a}=1}^{k_{\mathrm{a}}} n_{\mathrm{a}} t_{\mathrm{a}}+\sum_{\mathrm{g}=1}^{k_{\mathrm{g}}} n_{\mathrm{g}} t_{\mathrm{g}}
$$


where $T_{m}$ is the melting point in K. Parameters $n_{c}, n_{\mathrm{a}}$ and $n_{\mathrm{g}}$ denote the number of cations, anions and side groups in the molecule while $t_{\mathrm{c}}, t_{\mathrm{a}}$ and $t_{\mathrm{g}}$ represent the group contribution of the cations, anions and substituents for the melting point, respectively. These group contributions are obtained by fitting the available experimental melting point data into Eq.15 using Eq.16 as the objective function.

$$
O . F .=\sum_{i=1}^{N}\left[\left(\left(\sum_{\mathrm{c}=1}^{k_{\mathrm{c}}} n_{\mathrm{c}} t_{\mathrm{c}}+\sum_{\mathrm{a}=1}^{k_{\mathrm{a}}} n_{\mathrm{a}} t_{\mathrm{a}}+\sum_{\mathrm{g}=1}^{k_{\mathrm{g}}} n_{\mathrm{g}} t_{\mathrm{g}}\right)-T_{m_{\exp }}\right)^{2}\right]_{i}
$$

A total set consist of 225 experimental melting point data for 111 ILs covering 6 cation cores, 13 anions and 3 side groups are used in this study. The uncertainty of these experimental melting points is $0.59 \%$ with a maximum value of $2.52 \%$, showing the reliability of the studied data points. Among these 225 data points, 162 data points for 75 ILs is used to correlate the proposed group contribution model (Eq.15) with an AARD (\%) of 4.70\%. Then, the rest of 63 data points for 26 ILs are employed as test set to evaluate this model. The resulting AARD (\%) of prediction is $7.09 \%$, showing sufficient prediction accuracy of the proposed model. For both training and test sets, comparison between experimental and calculated melting points of ILs and their corresponding distributions of relative deviations between experimental data and model calculations are presented, as shown in Figure 9.

An overall AARD of $4.7 \%$ is achieved by using all substances (111ILs) as regression set, and the relationship between experimental and calculated melting point for all 225 data points is shown in Figure 10a. Figure 10b gives the relationship between RD (\%) and experimental melting points that provides more information of the proposed melting point estimation method. Among all 225 data points, $64.2 \%$ of the correlated melting points are within relative deviation of $0.0-5.0 \%$, $23.6 \%$ within $5.0-10.0 \%$, 9.8\% within $10.0-15.0 \%$, and only $4.9 \%$ of the calculated melting points having larger than $15.0 \%$ deviation. The maximum relative deviation is $20.3 \%$ observed for Tetrapropylammonium bis(trifluoromethylsulfonyl)imide ([Am(3)333][Tf $2 \mathrm{~N}])$.

Table 5 shows the calculated results of the group contribution parameters $t_{\mathrm{c}}, t_{\mathrm{a}}$ and $t_{\mathrm{g}}$ for melting point of ILs using all 225 data points as correlation set. As the side chain length increases on the cation, the melting point of ILs decreases, however, it will increase dramatically when group $-\mathrm{CH}_{3}$ attached directly to the cation (- $\mathrm{CH}_{3}$ (ring)) is present, which is validated by the group contributions of $-\mathrm{CH}_{3},-\mathrm{CH}_{2}$ - and $-\mathrm{CH}_{3}$ (ring). For ILs having same anion and similar side groups on the cation, the melting point increases with cation following the order: Imidazolium $<$ Pyrrolidinium $<$ Pyridinium $<$ Tetramethyl ammonium $<$ Tetramethyl phosphonium $<$ Piperidinium.

Table 5: Generated group contribution parameters $t_{c}, t_{\mathrm{a}}$ and $t_{\mathrm{g}}$ for Eq.15

\begin{tabular}{llllll}
\hline & $\mathrm{t}_{\mathrm{c}}, \mathrm{t}_{\mathrm{a}}(\mathrm{K})$ & & $\mathrm{t}_{\mathrm{a}}(\mathrm{K})$ & & $\mathrm{t}_{\mathrm{a}}, \mathrm{t}_{\mathrm{g}}(\mathrm{K})$ \\
\hline Cations & & Anions & & Anions & \\
Imidazolium (+) & 249.704 & {$\left[\mathrm{BF}_{4}\right]^{-}$} & 40.001 & {$\left[\mathrm{~N}(\mathrm{CN})_{2}\right]^{-}$} & 21.607 \\
Pyridinium (+) & 279.704 & {$\left[\mathrm{PF}_{6}\right]^{-}$} & 66.454 & {$\left[\mathrm{C}(\mathrm{CN})_{3}\right]^{-}$} & 14.151 \\
Pyrrolidinium (+) & 260.259 & {$[\mathrm{Cl}]^{-}$} & 94.707 & {$\left[\mathrm{AlCl}_{4}\right]^{-}$} & 31.601 \\
Tetramethyl ammonium (+) & 289.007 & {$[\mathrm{Ac}]^{-}$} & 6.707 & {$\left[\mathrm{Pf}_{2} \mathrm{~N}^{-}\right.$} & 24.101 \\
Tetramethyl phosphonium (+) & 297.262 & {$\left[\mathrm{MeSO}_{4}\right]^{-}$} & 20.901 & Substituents $^{-}$ \\
Piperidinium (+) & 364.333 & {$\left[\mathrm{CF}_{3} \mathrm{SO}_{3}\right]^{-}$} & 22.651 & $-\mathrm{CH}_{3}$ & -27.747 \\
Anions & & {$\left[\mathrm{Br}^{-}\right.$} & 105.407 & $-\mathrm{CH}_{2}-$ & -1.303 \\
[Tf $_{2} \mathrm{~N}^{-}$ & 22.757 & {$\left[\mathrm{CF}_{3} \mathrm{COO}^{-}\right.$} & 23.969 & $-\mathrm{CH}_{3}(\mathrm{ring})$ & 27.345 \\
\hline
\end{tabular}



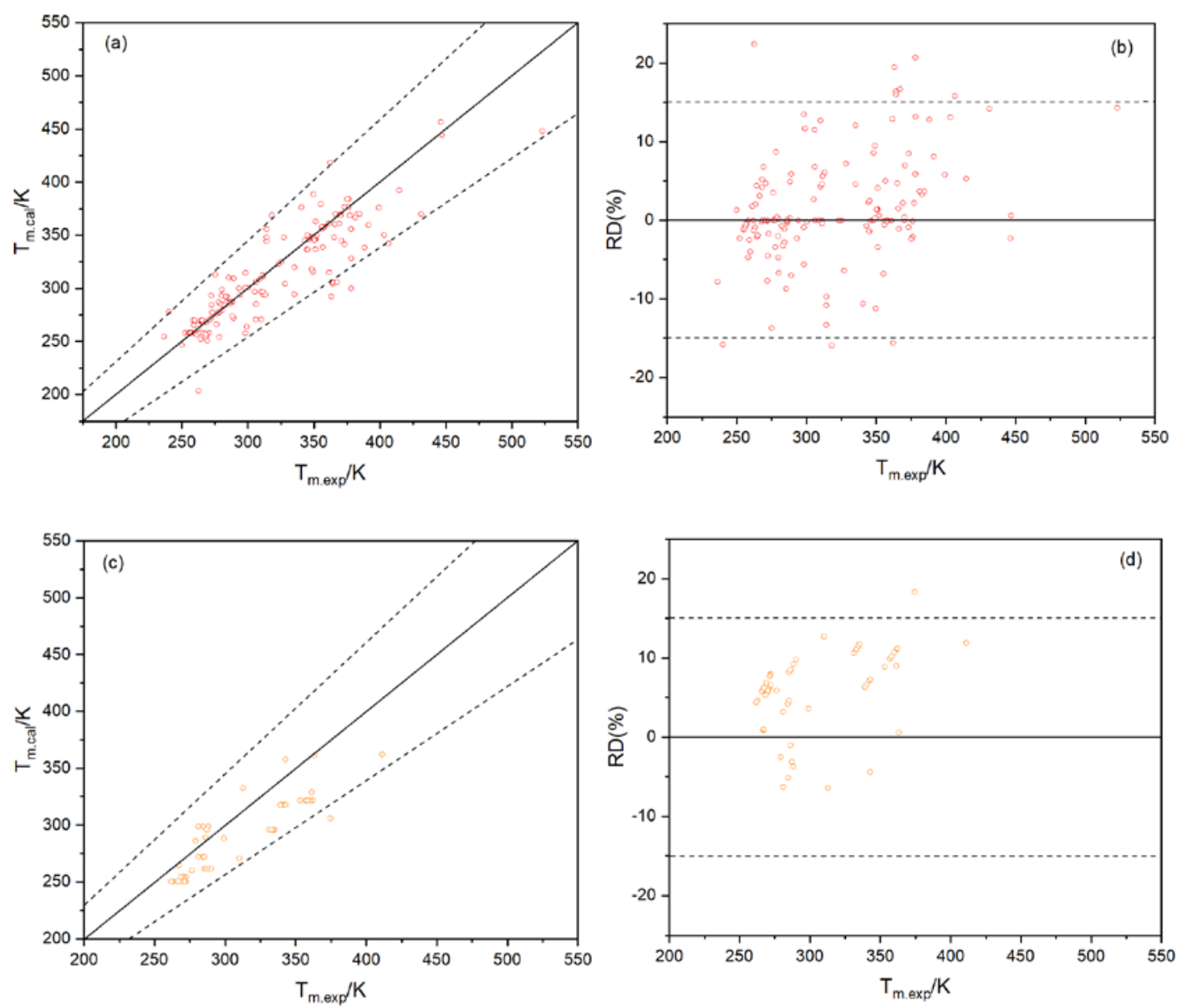

Figure 9. Plots of experimental versus calculated melting point for ILs and relative deviations between experimental and calculated data obtained by using Eq.15: (a) training set; (b) relative deviations for training set; (c) test set; (d) and relative deviations for test set. Dashed lines correspond to $\pm 15 \%$ of relative deviation.
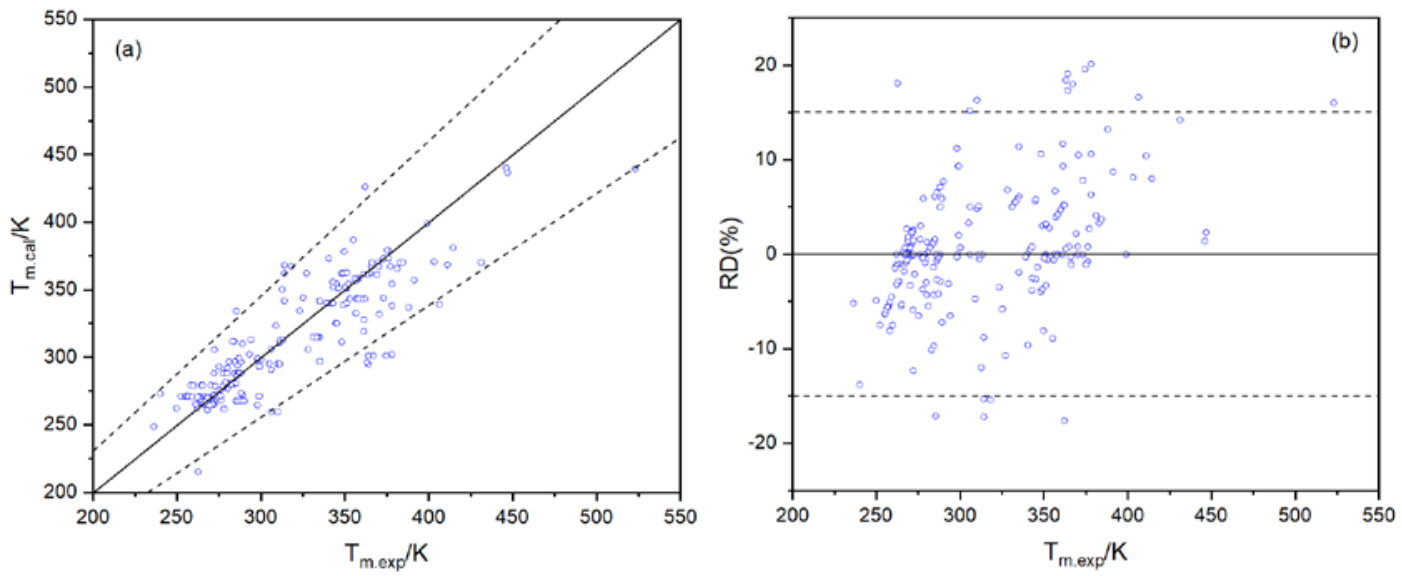

Figure 10. (a) Comparison between experimental and calculated melting point for all 225 data points and (b) relative deviations between the experimental and calculated melting point as a function of experimental data of melting point used in Eq.15. Dashed lines correspond to $\pm 15 \%$ of relative deviation. 
A summary of property estimation of ILs using group contribution methods proposed in this work is given in Table 7, in which the number of fitted data points and the AARD\% of each cation based ILs as well as all families for the studied properties are provided. To contrast the performance of the developed methods with some other corresponding methods from literature, we compiled the number of fitted and predicted data points, the required related information, the AARD\% and the maximum relative deviation of all estimated methods for each property, shown as in Table 8. The comparisons reflect the reliability and the simplicity of the group contribution methods for studied properties proposed in this work.

Table 7. Summary of property correlation of ILs using the group contribution methods proposed in this work

\begin{tabular}{|c|c|c|c|}
\hline Properties & Cation-based & Data points & $\begin{array}{l}\text { Average Absolute } \\
\text { Relative Deviation (\%) }\end{array}$ \\
\hline \multirow{7}{*}{ Density } & Imidazolium- & 5061 & 0.44 \\
\hline & Pyridinium- & 990 & 0.63 \\
\hline & Pyrrolidinium- & 457 & 0.97 \\
\hline & Alkyl ammonium- & 204 & 1.59 \\
\hline & Phosphonium- & 424 & 0.11 \\
\hline & Piperidinium- & 224 & 0.19 \\
\hline & All families & 7360 & 0.50 \\
\hline \multirow{7}{*}{ Heat capacity } & Imidazolium- & 2672 & 0.36 \\
\hline & Pyridinium- & 442 & 0.99 \\
\hline & Pyrrolidinium- & 88 & 0.07 \\
\hline & Alkyl ammonium- & 31 & 0.40 \\
\hline & Phosphonium- & 48 & 0.13 \\
\hline & Piperidinium- & 23 & 0.11 \\
\hline & All families & 3304 & 0.43 \\
\hline \multirow{7}{*}{ Viscosity } & Imidazolium- & 476 & 4.22 \\
\hline & Pyridinium- & 280 & 3.27 \\
\hline & Pyrrolidinium- & 65 & 3.58 \\
\hline & Alkyl ammonium- & 149 & 3.35 \\
\hline & Phosphonium- & 64 & 2.00 \\
\hline & Piperidinium- & 56 & 2.89 \\
\hline & All families & 1090 & 3.58 \\
\hline \multirow{7}{*}{ Surface tension } & Imidazolium- & 753 & 2.96 \\
\hline & Pyridinium- & 281 & 2.13 \\
\hline & Pyrrolidinium- & 114 & 1.50 \\
\hline & Alkyl ammonium- & 111 & 4.39 \\
\hline & Phosphonium- & 85 & 8.76 \\
\hline & Piperidinium- & 21 & 0.66 \\
\hline & All families & 1365 & 3.10 \\
\hline \multirow{7}{*}{ Melting point } & Imidazolium- & 125 & 3.64 \\
\hline & Pyridinium- & 23 & 5.87 \\
\hline & Pyrrolidinium- & 22 & 5.48 \\
\hline & Alkyl ammonium- & 41 & 7.05 \\
\hline & Phosphonium- & 9 & 5.34 \\
\hline & Piperidinium- & 5 & 3.80 \\
\hline & All families & 225 & 4.74 \\
\hline
\end{tabular}


Table 8. Comparisons between the methods proposed in this work and other methods from literature

\begin{tabular}{|c|c|c|c|c|c|c|c|}
\hline Properties & Author(s) & Sets & $\begin{array}{l}\text { Data } \\
\text { Points }\end{array}$ & ILs & $\begin{array}{l}\text { AARD } \\
(\%)\end{array}$ & $\begin{array}{l}|\mathrm{RD}|_{\max } \\
(\%)\end{array}$ & $\begin{array}{l}\text { Related } \\
\text { Information } \\
\text { Required }\end{array}$ \\
\hline \multirow{6}{*}{ Density } & \multirow{3}{*}{$\begin{array}{l}\text { Paduszynski- } \\
\text { Domanska }^{48}\end{array}$} & Training & 13135 & 828 & 0.53 & $\approx 15.00$ & \multirow{3}{*}{$\begin{array}{l}\text { Molar mass } \\
\text { Molar volume }\end{array}$} \\
\hline & & Test & 3695 & 200 & 0.45 & $\approx 12.50$ & \\
\hline & & Total & 16830 & 1028 & 0.51 & & \\
\hline & \multirow{3}{*}{ This work } & Training & 5039 & 90 & 0.43 & 4.70 & \multirow{3}{*}{ No } \\
\hline & & Test & 2321 & 53 & 0.67 & 6.24 & \\
\hline & & Total & 7360 & 143 & 0.49 & 4.60 & \\
\hline \multirow{4}{*}{$\begin{array}{l}\text { Heat } \\
\text { capacity }\end{array}$} & $\begin{array}{l}\text { Gardas- } \\
\text { Coutinho }^{35}\end{array}$ & Total & 2396 & 19 & 0.36 & 2.43 & No \\
\hline & \multirow{3}{*}{ This work } & Training & 2391 & 44 & 0.39 & 4.20 & \multirow{3}{*}{ No } \\
\hline & & Test & 913 & 17 & 0.62 & 4.70 & \\
\hline & & Total & 3304 & 61 & 0.43 & 4.60 & \\
\hline \multirow{4}{*}{ Viscosity } & $\begin{array}{l}\text { Gardas- } \\
\text { Coutinho }^{36}\end{array}$ & Total & 482 & 24 & 7.50 & 22.79 & No \\
\hline & & Training & 778 & 56 & 3.36 & 27.50 & \multirow{3}{*}{ No } \\
\hline & This work & Test & 312 & 20 & 5.63 & 36.80 & \\
\hline & & Total & 1090 & 76 & 3.58 & 27.70 & \\
\hline \multirow{4}{*}{$\begin{array}{l}\text { Surface } \\
\text { tension }\end{array}$} & $\begin{array}{l}\text { Gardas- } \\
\text { Coutinho }^{49}\end{array}$ & Total & 361 & 40 & 5.75 & 15.58 & \multirow[t]{2}{*}{$\begin{array}{l}\text { Parachors } \\
\text { Density }\end{array}$} \\
\hline & \multirow{3}{*}{ This work } & Training & 952 & 72 & 2.87 & 19.92 & \\
\hline & & Test & 413 & 30 & 4.71 & 14.70 & \multirow[t]{2}{*}{ No } \\
\hline & & Total & 1365 & 102 & 3.10 & 22.10 & \\
\hline \multirow{6}{*}{$\begin{array}{l}\text { Melting } \\
\text { point }\end{array}$} & \multirow{6}{*}{ This work } & Training & 200 & 200 & 7.97 & 25.17 & \multirow{3}{*}{ No } \\
\hline & & Test & 200 & 200 & 6.16 & 19.47 & \\
\hline & & Total & 400 & 400 & 7.07 & 25.17 & \\
\hline & & Training & 162 & 75 & 4.70 & 22.40 & \multirow{3}{*}{ No } \\
\hline & & Test & 63 & 26 & 7.09 & 18.30 & \\
\hline & & Total & 225 & 111 & 4.74 & 20.30 & \\
\hline
\end{tabular}

\section{Conclusion}

Group contribution property estimation methods for the density, heat capacity, viscosity, surface tension and melting point of ILs have been developed. More than 13300 experimental data points from about 200 ILs covering 6 cations, 19 anions and 4 substituents in a wide range of temperature (and pressure) were used to generate the group contribution parameters. The calculation results of both correlation and prediction sets, presented as the comparison between the experimental and calculated properties of ILs as well as distributions of relative deviations between experimental data and model calculations, showing the good predictive capability of the proposed group contribution methods. A summary of property estimation of ILs using group contribution methods proposed in this work is provided and comparisons between these methods with some other corresponding methods for all studied properties from literature are presented to validate the performance of the estimated methods proposed in this work.

The group contribution methods presented in this work can predict the properties of both well-known ILs and for those never previously studied, which make it possible to use CAMD methods for identifying the potential optimal ILs rapidly and confidently in specific applications involving ILs. 
These methods can be further extended to new ILs that are not included in this study once their experimental data become available.

\section{Acknowledgements}

This research work was supported by the China Scholarship Council (No. 201708440264) and the Technical University of Denmark. The authors would like to thank PhD student Nipun Garg from the Technical University of Denmark. His suggestions and comments were much appreciated.

\section{Supporting Information}

Tables summarizing the information (e.g. names of ILs, and a list of literature sources to experimental data) of all ILs involved in the models development. The information also includes the calculation results of each IL for all considered properties (density, heat capacity, viscosity, surface tension and melting point).

\section{References}

(1) Rogers, R. D.; Seddon, K. R.: Ionic liquids--solvents of the future? Science 2003, 302, 792-793.

(2) Liu, Z.; Meng, X.; Zhang, R.; Xu, C.; Dong, H.; Hu, Y.: Reaction performance of isobutane alkylation catalyzed by a composite ionic liquid at a short contact time. AIChE Journal 2014, 60, 2244-2253.

(3) Xiong, J.; Zhu, W.; Li, H.; Xu, Y.; Jiang, W.; Xun, S.; Liu, H.; Zhao, Z.: Immobilized fenton - like ionic liquid: Catalytic performance for oxidative desulfurization. AIChE Journal 2013, 59, 4696-4704.

(4) Devi, B. P.; Guo, Z.; Xu, X.: Characterization of ionic liquid - based biocatalytic two - phase reaction system for production of biodiesel. AIChE Journal 2011, 57, 1628-1637.

(5) Ortiz - Martínez, V.; Salar - García, M.; Hernández - Fernández, F.; Olivares - Carrillo, P.; de Los Ríos, A.; Quesada - Medina, J.: Ionic liquids in supercritical methanol greatly enhance transesterification reaction for high - yield biodiesel production. AIChE Journal 2016, 62, 3842-3846.

(6) Brogan, A. P.; Bui-Le, L.; Hallett, J. P.: Non-aqueous homogenous biocatalytic conversion of polysaccharides in ionic liquids using chemically modified glucosidase. Nature Chemistry 2018, 10, 859.

(7) Xu, P.; Du, P.-X.; Zong, M.-H.; Li, N.; Lou, W.-Y.: Combination of deep eutectic solvent and ionic liquid to improve biocatalytic reduction of 2-octanone with Acetobacter pasteurianus GIM1. 158 cell. Scientific reports 2016, 6, 26158.

(8) Lee, B. S.; Lin, S. T.: Prediction and screening of solubility of pharmaceuticals in single - and mixed ionic liquids using COSMO - SAC model. AIChE Journal 2017, 63, 3096-3104.

(9) Feng, G.; Li, S.; Zhao, W.; Cummings, P. T.: Microstructure of room temperature ionic liquids at stepped graphite electrodes. AIChE Journal 2015, 61, 3022-3028.

(10) Rosen, B. A.; Salehi-Khojin, A.; Thorson, M. R.; Zhu, W.; Whipple, D. T.; Kenis, P. J.; Masel, R. I.: Ionic liquid-mediated selective conversion of CO2 to CO at low overpotentials. Science 2011, 1209786.

(11) Armand, M.; Endres, F.; MacFarlane, D. R.; Ohno, H.; Scrosati, B.: Ionic-liquid materials for the electrochemical challenges of the future. In Materials For Sustainable Energy: A Collection of Peer-Reviewed Research and Review Articles from Nature Publishing Group; World Scientific, 2011; pp 129-137.

(12) Thoms, E.; Sippel, P.; Reuter, D.; Weiß, M.; Loidl, A.; Krohns, S.: Dielectric study on mixtures of ionic liquids. Scientific reports 2017, 7, 7463.

(13) Mortazavi - Manesh, S.; Satyro, M. A.; Marriott, R. A.: Screening ionic liquids as candidates for separation of acid gases: solubility of hydrogen sulfide, methane, and ethane. AIChE Journal 2013, 59, 29933005.

(14) Song, Z.; Zhang, C.; Qi, Z.; Zhou, T.; Sundmacher, K.: Computer - aided design of ionic liquids as solvents for extractive desulfurization. AIChE Journal 2018, 64, 1013-1025.

(15) Zhao, Y.; Gani, R.; Afzal, R. M.; Zhang, X.; Zhang, S.: Ionic liquids for absorption and separation of gases: An extensive database and a systematic screening method. AIChE Journal 2017, 63, 1353-1367.

(16) Hernández - Fernández, F.; de Los Ríos, A.; Gómez, D.; Rubio, M.; Víllora, G.: Selective extraction of organic compounds from transesterification reaction mixtures by using ionic liquids. AIChE journal 2010, 56, 1213-1217.

(17) Pereiro, A. B.; Rodríguez, A.: An ionic liquid proposed as solvent in aromatic hydrocarbon separation by liquid extraction. AIChE journal 2010, 56, 381-386. 
(18) Anantharaj, R.; Banerjee, T.: Aromatic sulfur - nitrogen extraction using ionic liquids: Experiments and predictions using an a priori model. AIChE Journal 2013, 59, 4806-4815.

(19) Fang, J.; Zhao, R.; Su, W.; Li, C.; Liu, J.; Li, B.: A molecular design method based on the COSMO SAC model for solvent selection in ionic liquid extractive distillation. AIChE Journal 2016, 62, 2853-2869.

(20) Lei, Z.; Dai, C.; Zhu, J.; Chen, B.: Extractive distillation with ionic liquids: a review. AIChE Journal 2014, 60, 3312-3329.

(21) Plechkova, N. V.; Seddon, K. R.: Applications of ionic liquids in the chemical industry. Chemical Society Reviews 2008, 37, 123-150.

(22) Gani, R.; Nielsen, B.; Fredenslund, A.: A group contribution approach to computer - aided molecular design. AIChE Journal 1991, 37, 1318-1332.

(23) Harper, P. M.; Gani, R.; Kolar, P.; Ishikawa, T.: Computer-aided molecular design with combined molecular modeling and group contribution. Fluid Phase Equilibria 1999, 158, 337-347.

(24) Karunanithi, A.; Mehrkesh, A.: Computer-Aided Design of Tailor-Made Ionic Liquids, 2013; Vol. 59.

(25) Jacquemin, J.; Ge, R.; Nancarrow, P.; Rooney, D. W.; Costa Gomes, M. F.; Pádua, A. A.; Hardacre, C.: Prediction of ionic liquid properties. I. Volumetric properties as a function of temperature at $0.1 \mathrm{MPa}$. Journal of Chemical \& Engineering Data 2008, 53, 716-726.

(26) Jacquemin, J.; Nancarrow, P.; Rooney, D. W.; Costa Gomes, M. F.; Husson, P.; Majer, V.; Pádua, A. A.; Hardacre, C.: Prediction of ionic liquid properties. II. Volumetric properties as a function of temperature and pressure. Journal of Chemical \& Engineering Data 2008, 53, 2133-2143.

(27) Qiao, Y.; Ma, Y.; Huo, Y.; Ma, P.; Xia, S.: A group contribution method to estimate the densities of ionic liquids. The Journal of Chemical Thermodynamics 2010, 42, 852-855.

(28) Gardas, R. L.; Coutinho, J. A.: Extension of the Ye and Shreeve group contribution method for density estimation of ionic liquids in a wide range of temperatures and pressures. Fluid Phase Equilibria 2008, 263, 2632.

(29) Lazzús, J. A.: $\rho-T-P$ prediction for ionic liquids using neural networks. Journal of the Taiwan Institute of Chemical Engineers 2009, 40, 213-232.

(30) Shen, C.; Li, C.-x.; Li, X.-m.; Lu, Y.-z.; Muhammad, Y.: Estimation of densities of ionic liquids using Patel-Teja equation of state and critical properties determined from group contribution method. Chemical engineering science 2011, 66, 2690-2698.

(31) Valderrama, J. O.; Zarricueta, K.: A simple and generalized model for predicting the density of ionic liquids. Fluid Phase Equilibria 2009, 275, 145-151.

(32) Abildskov, J.; Ellegaard, M. D.; O’Connell, J. P.: Densities and isothermal compressibilities of ionic liquids-modeling and application. Fluid Phase Equilibria 2010, 295, 215-229.

(33) Ji, X.; Adidharma, H.: Thermodynamic modeling of ionic liquid density with heterosegmented statistical associating fluid theory. Chemical Engineering Science 2009, 64, 1985-1992.

(34) Wang, J.; Li, Z.; Li, C.; Wang, Z.: Density prediction of ionic liquids at different temperatures and pressures using a group contribution equation of state based on electrolyte perturbation theory. Industrial \& Engineering Chemistry Research 2010, 49, 4420-4425.

(35) Gardas, R. L.; Coutinho, J. A.: A group contribution method for heat capacity estimation of ionic liquids. Industrial \& Engineering Chemistry Research 2008, 47, 5751-5757.

(36) Gardas, R. L.; Coutinho, J. A.: Group contribution methods for the prediction of thermophysical and transport properties of ionic liquids. AIChE Journal 2009, 55, 1274-1290.

(37) Gardas, R. L.; Coutinho, J. A.: A group contribution method for viscosity estimation of ionic liquids. Fluid Phase Equilibria 2008, 266, 195-201.

(38) Yu, G.; Zhao, D.; Wen, L.; Yang, S.; Chen, X.: Viscosity of ionic liquids: Database, observation, and quantitative structure - property relationship analysis. AIChE Journal 2012, 58, 2885-2899.

(39) Benjamin, I.: Chemical reactions and solvation at liquid interfaces: A microscopic perspective. Chemical reviews 1996, 96, 1449-1476.

(40) Kuzmenko, I.; Rapaport, H.; Kjaer, K.; Als-Nielsen, J.; Weissbuch, I.; Lahav, M.; Leiserowitz, L.: Design and characterization of crystalline thin film architectures at the air- liquid interface: Simplicity to complexity. Chemical Reviews 2001, 101, 1659-1696.

(41) Madeira Lau, R.; Van Rantwijk, F.; Seddon, K.; Sheldon, R.: Lipase-catalyzed reactions in ionic liquids. Organic Letters 2000, 2, 4189-4191.

(42) Gardas, R. L.; Coutinho, J. A.: Applying a QSPR correlation to the prediction of surface tensions of ionic liquids. Fluid Phase Equilibria 2008, 265, 57-65.

(43) Antony, J. H.; Mertens, D.; Dölle, A.; Wasserscheid, P.; Carper, W. R.: Molecular Reorientational Dynamics of the Neat Ionic Liquid 1 - Butyl - 3 - methylimidazolium Hexafluorophosphate by Measurement of 13C Nuclear Magnetic Relaxation Data. ChemPhysChem 2003, 4, 588-594.

(44) Lazzús, J. A.: Hybrid method to predict melting points of organic compounds using group contribution+ neural network+ particle swarm algorithm. Industrial \& Engineering Chemistry Research 2009, 48, 8760-8766.

(45) Katritzky, A. R.; Lomaka, A.; Petrukhin, R.; Jain, R.; Karelson, M.; Visser, A. E.; Rogers, R. D.: QSPR correlation of the melting point for pyridinium bromides, potential ionic liquids. Journal of chemical information and computer sciences 2002, 42, 71-74. 
(46) Carrera, G.; Aires-de-Sousa, J.: Estimation of melting points of pyridinium bromide ionic liquids with decision trees and neural networks. Green Chemistry 2005, 7, 20-27.

(47) Lazzús, J. A.: A group contribution method to predict the melting point of ionic liquids. Fluid Phase Equilibria 2012, 313, 1-6.

(48) Paduszynski, K.; Domanska, U.: A new group contribution method for prediction of density of pure ionic liquids over a wide range of temperature and pressure. Industrial \& Engineering Chemistry Research 2011, 51, 591-604.

(49) Gardas, R. L.; Coutinho, J. A.: Applying a QSPR correlation to the prediction of surface tensions of ionic liquids. Fluid Phase Equilibria 2008, 265, 57-65.

(50) Gaciño, F. l. M.; Regueira, T.; Lugo, L.; Comuñas, M. a. J.; Fernández, J.: Influence of molecular structure on densities and viscosities of several ionic liquids. Journal of Chemical \& Engineering Data 2011, 56, 4984-4999.

(51) Mahrova, M.; Vilas, M.; Dominguez, A.; Gómez, E.; Calvar, N.; Tojo, E.: Physicochemical characterization of new sulfonate and sulfate ammonium ionic liquids. Journal of Chemical \& Engineering Data 2012, 57, 241-248.

(52) Tenney, C. M.; Massel, M.; Mayes, J. M.; Sen, M.; Brennecke, J. F.; Maginn, E. J.: A computational and experimental study of the heat transfer properties of nine different ionic liquids. Journal of Chemical \& Engineering Data 2014, 59, 391-399.

(53) Součková, M.; Klomfar, J.; Pátek, J.: Surface tension and 0.1 MPa density for members of homologous series of ionic liquids composed of imidazolium-, pyridinium-, and pyrrolidinium-based cations and of cyanogroups containing anions. Fluid Phase Equilibria 2015, 406, 181-193.

(54) Kato, H.; Miki, K.; Mukai, T.; Nishikawa, K.; Koga, Y.: Hydrophobicity/hydrophilicity of 1-butyl-2, 3dimethyl and 1-ethyl-3-methylimodazolium ions: toward characterization of room temperature ionic liquids. The Journal of Physical Chemistry B 2009, 113, 14754-14760.

\section{Appendix A: Calculation Examples}

Example 1. Density calculation

1-butyl-2,3-dimethylimidazolium bis(trifluoromethylsulfonyl)imide ([C4mmIm][Tf $2 \mathrm{~N}])$ at $298.15 \mathrm{~K}$ and 0.1 Mpa

\begin{tabular}{lcccc}
\hline Group Assignment & & & & \\
& $n_{i}$ & $a_{i . \rho}\left(\mathrm{kg} \cdot \mathrm{m}^{-3}\right)$ & $\mathrm{b}_{i . \rho}\left(\mathrm{kg} \cdot \mathrm{m}^{-3} \cdot \mathrm{K}^{-1}\right)$ & $c_{i . \rho}\left(\mathrm{kg} \cdot \mathrm{m}^{-3} \cdot \mathrm{Mpa}^{-1}\right)$ \\
\hline Substituents & 1 & -66.767 & 0.163 & -0.274 \\
$-\mathrm{CH}_{3}$ & 3 & -40.521 & 0.030 & -0.020 \\
$-\mathrm{CH}_{2-}$ & & & & \\
Cations & 1 & $1.099 \times 10^{3}$ & 3.956 & 6.687 \\
$\begin{array}{l}1,3-\text { dimethylimidazolium (+) } \\
\text { Anions }\end{array}$ & & & & -5.969 \\
{$\left[\mathrm{Tf}_{2} \mathrm{~N}\right]^{-}$} & 1 & 724.274 & -4.933 & \\
\hline
\end{tabular}

$A_{\rho}=\sum_{i=1}^{k} n_{i} a_{i, \rho}=-66.767+(-40.521 \times 3)+1099+724.274=1634.944$

$B_{\rho}=\sum_{i=1}^{k} n_{i} b_{i, \rho}=0.163+0.030 \times 3+3.956+(-4.933)=-0.724$

$C_{\rho}=\sum_{i=1}^{k} n_{i} c_{i, \rho}=(-0.274)+(-0.020 \times 3)+6.687+(-5.969)=0.567$

$\rho=A_{\rho}+B_{\rho} \cdot T+C_{\rho} \cdot P=1634.944+(-0.724) \times 298.15+0.567 \times 0.1=1419.14 \mathrm{~kg} \cdot \mathrm{m}^{-3}$

Experimental value $^{50}: 1419.40 \mathrm{~kg} \cdot \mathrm{m}^{-3}$

Relative deviation $0.018 \%$ 
Example 2. Heat capacity calculation

N-ethyl-N,N-dimethyl-N-butylammonium ethyl sulfate [Am(1)124][EtSO4] ) at 390.15K

\begin{tabular}{lcccc}
\hline Group Assignment & & & & \\
& $n_{i}$ & $a_{i . C p L}$ & $b_{i . C p L}\left(\mathrm{~K}^{-1}\right)$ & $d_{i . C p L}\left(\mathrm{~K}^{-2}\right)$ \\
\hline $\begin{array}{l}\text { Substituents } \\
-\mathrm{CH}_{2}-\end{array}$ & 4 & 5.347 & -1.36 & 0.295 \\
$\begin{array}{l}\text { Cations } \\
\text { Tetramethyl } \\
\text { ammonium (+) }\end{array}$ & 1 & 106.569 & -71.423 & 4.062 \\
$\begin{array}{l}\text { Anions } \\
{\left[\text { EtSO }_{4}\right]^{-}}\end{array}$ & 1 & 16.916 & 20.05 & \\
\hline
\end{tabular}

$A_{C_{p L}}=\sum_{i=1}^{k} n_{i} a_{i .} c_{p L}=5.347 \times 4+106.569+16.916=144.873$

$B_{C_{p L}}=\sum_{i=1}^{k} n_{i} b_{i .} C_{p L}=(-1.36 \times 4)+(-71.423)+20.05=-56.813$

$D_{C_{p L}}=\sum_{i=1}^{k} n_{i} c_{i .} c_{p L}=0.295 \times 4+4.062+3.752=8.994$

$C_{p L}=R\left(A_{C_{p L}}+B_{C_{p L}}\left(\frac{T}{100}\right)+D_{C_{p L}}\left(\frac{T}{100}\right)^{2}\right)=8.3145 \times\left(144.873+(-56.813) \times \frac{390.15}{100}+8.994 \times\right.$

$\left.\left(\frac{390.15}{100}\right)^{2}\right)=499.88 \mathrm{~J} \cdot \mathrm{mol}^{-1} \cdot \mathrm{K}^{-3}$

Experimental value ${ }^{51}: 500.00 \mathrm{~J} \cdot \mathrm{mol}^{-1} \cdot \mathrm{K}^{-3}$

Relative deviation $0.025 \%$

Example 3. Viscosity calculation

1-butyl-4-(N',N'-dimethylammonium) pyridinium bis(trifluoromethylsulfonyl)imide ([ $\left.\left.\mathrm{C}_{4}(\mathrm{dmN}) \mathrm{Py}\right]\left[\mathrm{Tf}_{2} \mathrm{~N}\right]\right)$ at $283 \mathrm{~K}$

\begin{tabular}{lcccc}
\hline Group Assignment & \multicolumn{2}{c}{$R_{0 \eta}=14.877$} & & \\
& $n_{i}$ & $a_{i . \eta}$ & $b_{i, \eta}(\mathrm{K})$ & $d_{i . \eta}\left(\mathrm{K}^{2}\right)$ \\
\hline Substituents & & & & \\
$-\mathrm{CH}_{2-}$ & 3 & -0.346 & 1.460 & 0.076 \\
$-\mathrm{dmN}$ & 1 & 5.319 & -35.574 & 61.498 \\
Cations & & & & \\
1-methylpyridinium (+) & 1 & 3.710 & -26.702 & 94.864 \\
$\begin{array}{l}\text { Anions } \\
\text { [Tf }_{2} \mathrm{~N}^{-}\end{array}$ & 1 & -8.316 & -16.355 & 21.492 \\
\hline
\end{tabular}

$$
\begin{aligned}
& A_{\eta}=\sum_{i=1}^{k} n_{i} a_{i . \eta}=(-0.346 \times 3)+5.319+3.71+(-8.316)=-0.325 \\
& B_{\eta}=\sum_{i=1}^{k} n_{i} b_{i . \eta}=1.46 \times 3+(-35.574)+(-26.702)+(-16.355)=-74.251
\end{aligned}
$$


$D_{\eta}=\sum_{i=1}^{k} n_{i} d_{i . \eta}=0.076 \times 3+61.498+94.864+21.492=178.082$

$\eta=\exp \left(A_{\eta}+B_{\eta} \frac{100}{T}+D_{\eta}\left(\frac{100}{T}\right)^{2}\right) * R_{0 \eta}=\left((-0.325)+(-74.251) \times \frac{100}{283}+178.082 \times\left(\frac{100}{283}\right)^{2}\right) \times 14.877$

$=0.197$ Pa.s

Experimental value $\mathrm{e}^{52}: 0.198 \mathrm{~Pa} . \mathrm{S}$

Relative deviation $0.51 \%$

Example 4. Surface tension calculation

1-butyl-1-methylpyrrolidinium tricyanomethanide $\left(\left[\mathrm{C}_{4} \mathrm{mPyr}\right]\left[\mathrm{C}(\mathrm{CN})_{3}\right]\right)$ at $263.32 \mathrm{~K}$

\begin{tabular}{lcccc}
\hline Group Assignment & & & & \\
& $n_{i}$ & $a_{i . \sigma}\left(\mathrm{N} \cdot \mathrm{m}^{-1}\right)$ & $b_{i . \sigma}\left(\mathrm{N} \cdot \mathrm{m}^{-1} \cdot \mathrm{K}^{-1}\right)$ & $d_{i . \sigma}\left(\mathrm{N}^{\left.-\mathrm{m}^{-1} \cdot \mathrm{K}^{-2}\right)}\right.$ \\
\hline $\begin{array}{l}\text { Substituents } \\
-\mathrm{CH}_{2-}\end{array}$ & 3 & -0.195 & 0.079 & -0.01 \\
$\begin{array}{l}\text { Cations } \\
\begin{array}{l}1,1-\text { dimethylpyrrolidinium (+) } \\
\text { Anions }\end{array}\end{array}$ & 1 & -1.882 & -0.092 & -0.19 \\
{$\left[\mathrm{C}(\mathrm{CN})_{3}\right]^{-}$} & 1 & 0.06 & -0.385 & 0.235 \\
\hline
\end{tabular}

$A_{\sigma}=\sum_{i=1}^{k} n_{i} a_{i . \sigma}=(-0.195 \times 3)+(-1.882)+0.06=-2.407$

$B_{\sigma}=\sum_{i=1}^{k} n_{i} b_{i . \sigma}=0.079 \times 3+(-0.092)+(-0.385)=-0.24$

$D_{\sigma}=\sum_{i=1}^{k} n_{i} d_{i . \sigma}=(-0.01) \times 3+(-0.19)+0.235=0.015$

$\sigma=\exp \left(A_{\sigma}+B_{\sigma}\left(\frac{T}{100}\right)+D_{\sigma}\left(\frac{T}{100}\right)^{2}\right)=\exp \left((-2.407)+(-0.24) \times \frac{263.32}{100}+0.015 \times\left(\frac{263.32}{100}\right)^{2}\right)=$ $0,05313 N \cdot m^{-1}$

Experimental value ${ }^{53}: 0.05296 N . \mathrm{m}^{-1}$

Relative deviation $0.33 \%$

Example 5. Melting point calculation

1-butyl-2,3-dimethylimidazolium chloride $\left.\left[\mathrm{C}_{4} \mathrm{mmIm}\right][\mathrm{Cl}]\right)$

\begin{tabular}{lcc}
\hline Group Assignment & & \\
& $n_{i}$ & $\mathrm{t}_{\mathrm{c}}, \mathrm{t}_{\mathrm{a}}, \mathrm{t}_{\mathrm{g}}(\mathrm{K})$ \\
\hline Substituents & 1 & -27.747 \\
$-\mathrm{CH}_{3}$ & 3 & -1.303 \\
$-\mathrm{CH}_{2}-$ & 2 & 27.345 \\
$-\mathrm{CH}_{3}$ (ring) & & \\
Cations & 1 & 249.704 \\
Imidazolium (+) & & \\
Anions & 1 & 94.707 \\
[Cl] $^{-}$ & & \\
\hline
\end{tabular}


$T_{m}=\sum_{\mathrm{c}=1}^{k_{\mathrm{c}}} n_{\mathrm{c}} t_{\mathrm{c}}+\sum_{\mathrm{a}=1}^{k_{\mathrm{a}}} n_{\mathrm{a}} t_{\mathrm{a}}+\sum_{\mathrm{g}=1}^{k_{\mathrm{g}}} n_{\mathrm{g}} t_{\mathrm{g}}=(-27.747)+(-1.303) \times 3+27.345 \times 2+$

$249.704+94.707=367.45 \mathrm{~K}$

Experimental value ${ }^{54}: 365.90 \mathrm{~K}$

Relative deviation $0.4 \%$ 


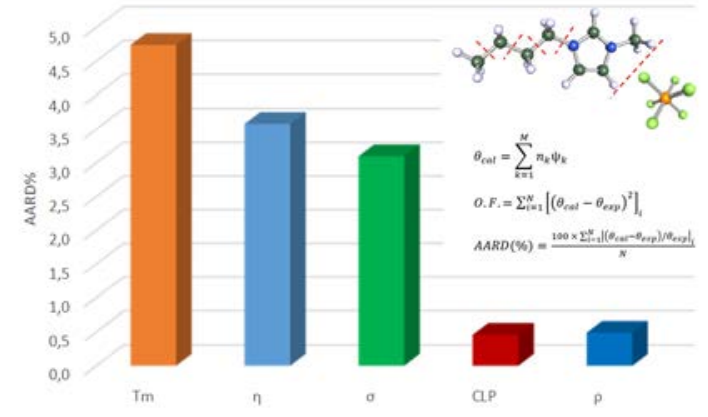

For Table of Contents Only 